\title{
What Explains Gender Gaps in Household Food Security? Evidence from Maize Farm Households in Southern Ethiopia
}

\author{
Girma Gezimu Gebre ${ }^{1,2}$ (D) Hiroshi Isoda ${ }^{3} \cdot$ Yuichiro Amekawa ${ }^{4} \cdot$ Dil Bahadur Rahut $^{5,6}$. \\ Hisako Nomura ${ }^{7} \cdot$ Takaaki Watanabe $^{3}$
}

Accepted: 23 December 2020 / Published online: 5 January 2021

(c) The Author(s) 2021

\begin{abstract}
Using primary data collected from 560 farm households in Dawuro zone, southern Ethiopia, this study analyzes the gender gaps in food security among male, female, and joint decision-making farm households. It examines the factors inducing gender gaps among the households of those three categories. The results show that female decision-making households have a lower probability of ensuring food-security and a higher probability of being transitionally and chronically food-insecure. Joint decision-making households showed a higher probability of falling into the chronically food-insecure category. The decomposition results show significant gender gaps between male and female decision-making households in terms of food-secure, transitory food-insecure, and chronically food-insecure categories. Overall, both the endowment and return effects account for the gaps; however, the magnitude of the effect from the return is higher than from the endowment on significant gaps in the food-secure, transitory, and chronically food-insecure categories. Hence, there is a need for policies that not only ensure equal levels of productive resources but also help households build their capacity in order to improve both transitory and chronically food insecure situations.
\end{abstract}

Keywords Gender · Food security · Maize · Decomposition model · Dawuro zone · Ethiopia

\section{Introduction}

Achieving gender equality and food security are mutually reinforcing objectives in the agenda of the Sustainable Development Goals of the United Nations-a blueprint for achieving a better and more sustainable future for all. To achieve them, a clearer understanding of gender dynamics, including gendered responsibilities, resource access and use, and associated constraints is critical to ensure the food security of women, who often fall behind men in their access to and benefits from agricultural enterprises and extension and financial services (World Bank et al. 2009; Peterman et al. 2010; Food

Girma Gezimu Gebre

girma.gezimu@gmail.com

Extended author information available on the last page of the article 
and Agriculture Organization (FAO) 2011; Ragasa et al. 2012; World Bank 2012; Asian Development Bank (ADB) 2013; Quisumbing et al. 2014; Agarwal 2015; Mukasa and Salami 2015; Njuki et al. 2016).

Women play an indispensable role in on-farm and off-farm activities, particularly in rural areas, contributing to the economic wellbeing and food security of their households (FAO et al. 2019). They account for approximately $43 \%$ of the agricultural labour force in developing countries (FAO 2011). However, the productivity of women in agriculture is often constrained by their limited access to productive resources (e.g., land, labour, fertilizer, improved seed, and machinery or capital) and services, which could have serious implications on the food security of their family and themselves (MeinzenDick et al. 2011; Agarwal 2015; Nijuki et al. 2016; Aryal et al. 2018). An analysis by FAO concluded that "if women had the same access to productive resources as men, they could increase yields on their farms by $20-30 \%$. This could increase total agricultural output in developing countries by $2.5-4 \%$, which could, in turn, reduce the number of hungry people in the world by 12-17\%" (FAO 2011, 5). However, a study by the World Bank (2014) on six African countries including Ethiopia revealed that equal access to productive resources such as fertilizer, farm labour, and training does not always translate into equal returns for female farmers. In most households, the agricultural production system is based on social norms and practices that determine the gender division of labour (Smith et al. 2003; FAO 2011; ADB 2013; Nijuki et al. 2016). For example, according to the Ethiopian tradition and culture, men are considered primary producers, while women are considered not farmers but helpers for the men working on the farm because they spend more time working in the homestead (Ragasa et al. 2012; Gebre et al. 2019b). Hence, there is a critical need for addressing gender inequalities in agriculture to ensure food security in developing countries.

According to the 1996 World Food Summit (WFS), food security exists "when all people at all times have access to sufficient, safe, and nutritious food to maintain an active and healthy life" (FAO 1996). This definition of food security has four dimensionsfood availability (presence of adequate food either through own production or purchase), access (food distribution within the household), utilization (food preparations including health and sanitation), and stability (access to adequate food throughout the whole day and year) (Westerweel and Samwel 2014). Women in agrarian households play a critical role in attaining each dimension of food security from production on the family plot, to food distribution between sale and self-consumption and food allocation within the household (Meinzen-Dick et al. 2011; ADB 2013).

However, women's roles in food production and distribution are determined by the power relations they are involved in within the household. Evidence shows that when women control household resources, they have a higher intrahousehold status and more influence over the household decisions, including decisions over production, distribution, and intrahousehold allocation of food, family nutrition, and use of income (Smith et al. 2003; FAO 2011; World Bank 2011). Moreover, Sraboni et al. (2014) noted that households that give more decision-making power to female spouses have a higher caloric availability and more dietary diversity. Such households allocate more resources for the production of food crops (Doss 2002). When the female spouse is in control over household financing, a higher percentage of household income is spent on food, health, and education of their family members than in the case of households without this control (Duflo and Udry 2004; FAO 2011). In agrarian societies, most agricultural production takes place at the household level (Njuguna et al. 2016), and men and women of farm households make either separate or joint decisions on food crop production (Aregu et al. 2011; Doss 2015). 
In the Dawuro community of southern Ethiopia, the decision-making processes of men and women in production and consumption are primarily determined by their household power relations. Agronomic activities that demand strong physicalities, such as plowing with oxen and planting, are considered men's tasks among the Dawuro community. Meanwhile, women are held responsible for childcare and other home tasks while sharing other less physically intensive agricultural activities with men (e.g., weeding, harvesting, collecting, and selling in the market. Taking advantage of the physical labour required to plow with oxen, men in the male-headed households tend to control much of the household agricultural production process as the major decision-maker in the household. In some maleheaded households that are noticeably resource-poor (e.g., land, oxen, etc.), or in some male-headed households where men are physically unable to plow with oxen for some reason, women make such decisions jointly with men. On rare occasions, women even make such decisions independently. In households where a female household head lives with adult sons, the sons plow their land using oxen. In households where a female-headed household does not live with adult sons, men from other households plow the female head's land using oxen in a form of sharecropping. ${ }^{1}$ In these two cases, because of their household resources (e.g., land and oxen) ownership, ${ }^{2}$ women make the major decisions in production and consumption. In some female-headed households, where women are more aged, their adult sons make such decisions either jointly or independently, depending on their responsibilities in the household. Thus, this study uses three gender-based decisionmaking categories of household crop production—male, female, and joint — as the indicators to examine gender-differentiated food security in the study area.

Using the primary data collected from four districts in Dawuro zone of southern Ethiopia, this study provides evidence on gender differences in food security by dividing 560 sampled farm households into three categories of maize producers: male, female, and joint decision-making households. Doing so, it seeks to answer the following research questions: (1) Are there any significant gender differences in food security among male, female, and joint decision-making households? If yes, which households exhibit the largest gender differences ?; and (2) What selected attributes related to access to resources and services (education, land, labour, livestock, credit, extension (training), improved seed, market information, off-farm incomes) and their associated

\footnotetext{
1 Sharecropping is a form of farming in which a landowner allows another farmer (tenant) to use his/her land in return for a portion of crop produced. In Dawuro community, sharecropping is based on the customary rule. For example, the proportion of crop share and cropping term depends on their agreement based on the rules traditionally developed and abided by.

2 As per the Federal Democratic Republic of Ethiopia (FDRE) constitution (Arts. 25, 34, 35 and 40), men and women have equal rights to own land entitlement (Tura 2014). Men and women (husband and wife) jointly own land entitlement within the household. Women (wife) also have a constitutional right to own land entitlement if their martial partner (husband) disappear or die. According to family law, all children (boys and girls) have equals right to inherit their parents land. Despite such a firm commitment of the government in recognizing a woman's right to possess and use rural lands, the customary laws and practices, which deny women's equality, are still persistent in the Dawuro community. As per Dawuro tradition, the land ownership usually belongs to the men (husband). Women (wife) generally lack legal awareness regarding their right to and control over household lands. Women do not have a customary right to inherit land from their family; and the control of land during marriage falls primarily under the control of their husband. Worst of all, after divorce, a rural woman has to leave her husband's home and look for another marriage without claiming her share of the matrimonial property. In this regard, the existing social norms permit significant gender biases in favor of men. Men typically inherit property rights of land and other assets of the household. Women (wife) normally own land entitlement in the absence of their male counterparts, whether due to the death of their husband, a husband's seasonal migration for wage work, or disappearance.
} 
returns account for the gender differences in food security among male, female, and joint decision-making households?

The proposed case is worth investigating for the following reasons. First, Ethiopia is a largely agrarian country, with a food insecurity prevalence rate of only $48.4 \%$ (FAO 2016). Second, maize is the most dominant cereal crop in terms of production (30\%) and the number of smallholders involved (over 9.5 million) in Ethiopia (Central Statistical Agency (CSA) 2019). It takes the highest share of national per capita calorie intake, accounting for $20 \%$ (World Food Program (WFP) and CSA 2019). The unit cost of calorie from maize is the cheapest among all major cereals including teff (eragrostis tef), wheat, barley, and sorghum in Ethiopia, making it the primary source of calorie and the most important food security crop for rural and/or resource-poor farm households (FAO 2015). These farm households use, on average, up to $75 \%$ of maize grain they have produced, for home consumption (Demeke 2012); no other cereal crop produce reaches this level of retention for home consumption (Jaleta et al. 2018). Third, women in Ethiopia play a significant role in maize production. For example, women in the Dawuro zone comprise, on average, $36 \%$ of the labour force in maize production (Gebre et al. 2019b) and $29 \%$ in all crop sectors in Ethiopia (Palacios-Lopez et al. 2017).

This paper contributes to the body of literature on gender gaps in food security in the following five ways. First, instead of using sex of the household head as the major gender indicator, we use the gender of major agricultural decision-makers in the household to examine the effect of intra-household dynamics on household food security. This approach is partly to eschew the proclivity that an approach stressing the household head as the gender indicator downplays the contributions of women in male-headed households and men in female-headed households, in making key decisions on household agricultural production. Second, in addition to the regression models that predict gender differences in food security based on the coefficient effects of binary gender variable, our study uses the Blinder-Oaxaca decomposition method, which allows decomposition of food security gaps into the portions driven from observable differences in resource levels (endowment effects) and returns from the use of those resources (coefficient or return effects). Third, we focus on farm households' self-reported subjective, rather than objective, food security status, which helps capture the seasonal variability of consumption, households' vulnerability, and the multidimensional nature of food security (Mallick and Rafi 2010; The Economist Intelligence Unit 2012). Fourth, in order to closely examine the insecure conditions of the surveyed households about their food access, we examined their situations in terms of two discrete household categories: transitory food-insecure and chronically food-insecure. This methodological approach parts company with most of the previous studies that simply classified households as either food-secure or insecure, which does not adequately capture the critical difference among the farm households laden with a food shortage. Fifth and last, as gender relations are context-specific and complex at multiple levels, it is difficult to design common policies that address gender-related inequalities in agriculture in a multi-cultural country such as Ethiopia; thus, our study focuses on a specific cultural context (i.e., Dawuro zone) of southern Ethiopia to examine the gender effects on household food security. Previous studies (e.g., Behrman et al. 2014) suggested that an analysis of the impacts of gender roles in agriculture should be more tailored and differentiated to take local contexts into adequate consideration.

The rest of the paper is organized as follows: Sect. 2 provides analytical frameworks of the study, Sect. 3 provides materials and methods, Sect. 4 presents results and discussion, and Sect. 5 concludes the paper. 


\section{Analytical Frameworks of the Study}

\subsection{Measuring the Gendered Food Security Gap}

There are several ways to measure food security, and these are broadly grouped into objective and subjective measurement methods. The majority of studies based on objective measures have used consumption or food expenditure data for measuring food security (e.g., Feleke et al. 2005; Pinstrup-Andersen 2009; Bogale and Shimelis 2009; Gebre 2012; Ogundari 2017; World Food Program (WFP) and CSA 2019). Consumption data tend to have large seasonal volatility, and such data are most often collected through a single-round survey undertaken in a specific month of the year. Household surveys of food security studies based on consumption data usually focus on either the 4-week or the seven-day duration prior to the start of survey interviews. Hence, consumption data could be subjected to problems related to infrequent purchases (where, for example, food is purchased shortly after the survey interview, consequently biasing the results of reported expenditure in the month prior to the interview). This could be coupled by measurement errors related to respondents' imperfect recall or reporting bias. Accordingly, consumption data may systematically under- or over-report the actual food security situation, depending on the time of the year the survey is conducted.

As an alternative set of measures, economists in recent years have made use of subjective assessments to estimate the state of food security (e.g., Mallick and Rafi 2010; Shiferaw et al. 2014; Kassie et al. 2014, 2015; Aryal et al. 2018; Jaleta et al. 2018; Broussard 2019; Lutomia et al. 2019). The use of the self-reported measurement is considered a better option because it provides a more inclusive and holistic picture of welfare than traditional objective measures such as consumption or income (e.g., Angner 2010; Frey and Stutzer 2002; Kahneman and Krueger 2006; Stutzer and Frey 2010; Van Hoorn et al. 2010). Studies have also shown that subjective well-being measures are correlated mostly in predictable ways with a variety of demographic, economic, and societal-level characteristics (e.g., Stutzer and Frey 2010), including per capita income (e.g., Kassie et al. 2015).

Recent studies on developing countries used the subjective measurement of food security (e.g., Mallick and Rafi 2010 in Bangladesh; Kassie et al. 2014 in Kenya; Kassie et al. 2015 in Malawi; Nkegbe et al. 2017 in Ghana; Aryal et al. 2018 in Bhutan; Jaleta et al. 2018 in Ethiopia). Likewise, this study used subjective food security measurement in order to capture the household food security status for 12 months preceding survey interviews. Following Mallick and Rafi (2010), the household food security perception status was defined based on the following question: "Taking into account all food sources (own production + food purchase + safety nets and welfare programmes + 'hidden harvest' from communal resources), how would you assess the household food consumption status in the past 12 months?" In our field survey, each respondent was asked to carefully assess the food security status of their family through subjective indicators which were grouped into the following four categories: (1) food surplus, (2) no food shortage nor surplus (food break-even), (3) occasional food shortage (transitory food insecurity), and (4) food shortage throughout the year (chronic food insecurity). 


\subsection{Empirical Framework}

To examine whether gender gaps remain in food security after controlling for other covariates, an ordered probit model is estimated to derive the probabilities related to the self-reported household food security status. This is because the outcome variables (food surplus, break-even, transitory food insecurity, and chronic food insecurity) are logically ordered. However, for analysis, we merge food surplus and break-even categories into food-secure households. ${ }^{3}$ Regarding food insecurity, as shown, households are classified into transitory food-insecure and chronically food-insecure households ${ }^{4}$ to capture the prevalence of food poverty in the study area. Accordingly, we have three ordered categories of outcome variables (food-secure, transitory food-insecure, and chronically food-insecure). Following Wooldridge (2010) and Greene (2012), the standard ordered probit equation is given as:

$$
Y_{i g}^{*}=X_{i g} \beta_{g}+\varepsilon_{i g}, \quad \varepsilon_{i g} \mid X_{\mathrm{ig}} \sim \operatorname{Normal}(0,1)
$$

where $Y_{i g}^{*}$ is a latent variable, $i$ represents either food-secure, transitory food-insecure, or chronically food-insecure farm households, $g$ represents gender indicator (male, female, or joint decision-makers), $X_{i g}$ is a vector of explanatory variables explaining the status of household-level food security, $\beta_{g}$ is coefficient and $\varepsilon_{i g}$ is the random error term. Let $\alpha_{1}<\alpha_{2}$, be unknown threshold parameters (cut points), and define the probability of respondent's self-reported food security status in Eq. (1) as:

$$
Y_{i g}= \begin{cases}0 \text { if } \mathrm{Y}_{\mathrm{ig}}^{*} \leq \alpha_{1}, & \text { food-secure } \\ 1 \text { if } \alpha_{1}<Y_{\mathrm{ig}}^{*} \leq \alpha_{2}, & \text { transitory food-insecure } \\ 2 \text { if } \mathrm{Y}_{\mathrm{ig}}^{*}>\alpha_{2}, & \text { chronically food-insecure }\end{cases}
$$

Given the normality assumption of $\varepsilon_{i g}$, the probability of observing each ordered response is:

$$
\begin{aligned}
& P\left(Y_{i g}=0 \mid X_{i g}\right)=P\left(Y_{i g}^{*} \leq \alpha_{1} \mid X_{i g}\right)=P\left(X_{i g} \beta_{g}+\varepsilon_{i g} \leq \alpha_{1} \mid X_{i g}\right)=\Phi\left(\alpha_{1}-X_{i g} \beta_{g}\right) \\
& P\left(Y_{i g}=1 \mid X_{i g}\right)=P\left(\alpha_{1}<Y_{i g}^{*} \leq \alpha_{2} \mid X_{i g}\right)=\Phi\left(\alpha_{2}-X_{i g} \beta_{g}\right)-\Phi\left(\alpha_{1}-X_{i g} \beta_{g}\right) \\
& P\left(Y_{i g}=2 \mid X_{i g}\right)=P\left(Y_{i g}^{*}>\alpha_{2} \mid X_{i g}\right)=1-\Phi\left(\alpha_{2}-X_{i g} \beta_{g}\right)
\end{aligned}
$$

Clearly, the sum of these probabilities is unity. With $1\left(Y_{i g}=0\right), 1\left(Y_{i g}=1\right)$ and $1\left(Y_{i g}=2\right)$ defined as indicator variables, the log-likelihood function for the parameter $\alpha$ and $\beta_{g}$ estimation is:

\footnotetext{
${ }^{3}$ In this study, food-secure households are considered to have year-round access to adequate food so as to meet the nutritional requirements of all household family members (i.e., father, mother, boys, girls, and children).

4 In this study, transitory food-insecure households refer to those households who are able to have sufficient food, but their food consumption is suddenly dropped due to seasonal variation, and/or economic or climate change effects such as drought, disease, or pest attacks. Chronically food-insecure households are defined as those who are unable to have sufficient food for their members throughout the year or longer.
} 


$$
\begin{aligned}
\ell_{i g}(\alpha, \beta)= & 1\left(Y_{i g}=0\right) \log \left[\Phi\left(\alpha_{1}-X_{i g} \beta_{g}\right)\right] \\
& +1\left(Y_{i g}=1\right) \log \left[\Phi\left(\alpha_{2}-X_{i g} \beta_{g}\right)-\Phi\left(\alpha_{1}-X_{i g} \beta_{g}\right)\right] \\
& +1\left(Y_{i g}=2\right) \log \left[1-\Phi\left(\alpha_{2}-X_{i g} \beta_{g}\right)\right]
\end{aligned}
$$

where $\Phi($.$) denotes the standards normal cumulative distribution function.$

As observed by Wooldridge (2010) and Greene (2012), the coefficient ( $\beta$ ) estimates from the ordered probit regression are not straightforward and are difficult to interpret. The coefficient estimates simply give the direction of explanatory variables on the outcome variables. It does not represent the actual magnitude of change associated with explanatory variables. Thus, by differentiating Eq. (3) with respect to explanatory variables, we identify the partial effects of each explanatory variables on the three probabilities, which can be estimated as:

$$
\begin{aligned}
& \frac{\partial \mathrm{P}\left(Y_{i g}=0 \mid X_{i g}\right)}{\partial X_{i g}}=-\varphi\left(\alpha_{1}-X_{i g} \beta_{g}\right) \beta_{g}, \\
& \frac{\partial \mathrm{P}\left(Y_{i g}=1 \mid X_{i g}\right)}{\partial X_{i g}}=\beta_{g}\left[\varphi\left(\alpha_{1}-X_{i g} \beta_{g}\right)-\varphi\left(\alpha_{2}-X_{i g} \beta_{g}\right)\right], \\
& \frac{\partial \mathrm{P}\left(Y_{i g}=2 \mid X_{i g}\right)}{\partial X_{i g}}=\varphi\left(\alpha_{2}-X_{i g} \beta_{g}\right) \beta_{g},
\end{aligned}
$$

where $\varphi($.$) denotes the standard normal density function.$

To investigate how gender differences in observable characteristics (resource levels) and its returns separately contribute to the gender gap in household food security status, the Blinder-Oaxaca (B-O) decomposition method, applicable to nonlinear regression models, was employed.

The B-O decomposition method has been used in labour economics literature to explain gender and racial differences in wages (Blinder 1973; Oaxaca 1973; Fairlie and Robb 2007). Recently, it was applied to explain gender gaps in agricultural productivity (e.g., Aguilar et al. 2015; Kilic et al. 2015; Mukasa and Salami 2015), in market participation (e.g., Marenya et al. 2017; Gebre et al. 2020), and in food security (e.g., Broussard 2019). The B-O decomposition method is used to compare the average gap between the two gender groups. However, in our case, we have three gender-based groups including male, female, and joint decision-making farm households with the discrete outcome variable. Hence, for simplification, let us take male and female decision-making groups. Following Sinning et al. (2008), the standard B-O decomposition of the gap between males and females in terms of the average value of an outcome variable can be expressed as:

$$
\text { Gap }=\bar{Y}_{m}-\bar{Y}_{f}=\underbrace{\left\{\left(\bar{X}_{m}-\bar{X}_{f}\right) \beta_{f}\right\}}_{\text {Endowment effect }(E)}+\underbrace{\left\{\bar{X}_{f}\left(\beta_{m}-\beta_{f}\right)\right\}}_{\text {Coefficient effect }(C)}+\underbrace{\left\{\left(\bar{X}_{m}-\bar{X}_{f}\right)\left(\beta_{m}-\beta_{f}\right)\right\}}_{\text {Interaction effect }(\mathrm{CE})}=E+C+\mathrm{CE}
$$

where $\bar{Y}$ is the average value of the outcome of interest, $\bar{X}_{g}$ is a vector of average values of observable characteristics, and $\beta_{g}$ is a vector of the coefficient estimates for gender $g$.

The first term of Eq. (6) captures the portion of the gender gap that owes to gender differences in endowment. The second term of Eq. (6) captures the portion of the gender gap that exists due to the differences in return or coefficient effects. The third term of Eq. (6) is the portion of gap attributable to the joint effects of both endowment and returns. Thus, it is assumed that these three factors help explain gender gaps in food security. 
However, when the outcome variable is binary and is estimated using nonlinear estimation techniques, the B-O decomposition method specified in Eq. (6) may not be appropriate, because $Y=F(X \beta), \bar{Y}$ may not equal $F(\bar{X} \beta)$. Hence, the recently developed (Fairlie 1999) and extended (Fairlie 2005) version of the B-O decomposition technique, which performs decomposition for the logit or probit model was used in this study. The decomposition for a nonlinear equation for the average probability of being food secure, transitory food insecure, or chronic food insecure $\overline{\mathrm{M}}=\Phi(\mathrm{X} \beta), \overline{\mathrm{M}}=\Phi(\mathrm{X} \beta), \overline{F S}=F(X \beta)$, can be expressed as:

$$
\begin{aligned}
\text { Gap }=F S_{m}-\overline{F S}_{f}= & \underbrace{\left\{\frac{1}{N_{m}} \sum_{i=1}^{N_{m}} F\left(X_{i m} \beta_{f}\right)-\frac{1}{N_{f}} \sum_{i=1}^{N_{f}} F\left(X_{i f} \beta_{f}\right)\right\}}_{\text {Endowment effect }(E)}+\underbrace{\left\{\frac{1}{N_{f}} \sum_{i=1}^{N_{f}} F\left(X_{i f} \beta_{m}\right)-\frac{1}{N_{f}} \sum_{i=1}^{N_{f}} F\left(X_{i f} \beta_{f}\right)\right\}}_{\text {Coefficient effect }(C)} \\
& +\underbrace{\left\{\frac{1}{N_{m}} \sum_{i=1}^{N_{m}} F\left(X_{i m} \beta_{m}\right)-\frac{1}{N_{m}} \sum_{i=1}^{N_{m}} F\left(X_{i m} \beta_{f}\right)\right\}+\left\{\frac{1}{N_{f}} \sum_{i=1}^{N_{f}} F\left(X_{i f} \beta_{m}\right)-\frac{1}{N_{f}} \sum_{i=1}^{N_{f}} F\left(X_{i f} \beta_{f}\right)\right\}}_{\text {Interaction effect (CE) }}
\end{aligned}
$$

where $\overline{F S}_{m}$ and $\overline{F S}_{f}$ denotes the average probability of being food-secure, transitory foodinsecure, or chronically food-insecure by male and female decision-making groups, $N_{g}$ is the sample size of gender $g$ and $F$ is the cumulative distribution function from the logit distribution. ${ }^{5}$ Similar to Eq. (6), Eq. (7) is a 'threefold' decomposition, where the mean gender gap in food security is divided into three components. ${ }^{6}$

Since the B-O model is formulated to decompose the mean outcome difference between the two groups, we decompose one group from the viewpoint of the other group. For example, the decompositions shown in Eqs. (6) and (7) are formulated from the perspective of female decision-makers. That is, the group differences in the predictors are weighed by the coefficients of female decision-makers $\left(\beta_{f}\right)$ to determine the endowment effects. The endowment effects measure the expected change in the female's mean outcome if a female has male predictor levels. Similarly, for the effects of the coefficients, the differences are weighed by female decision-makers' predictor $\left(X_{i f}\right)$ levels. The coefficient effect measures the expected change in female's mean outcome if a female had male coefficients. A positive value of the return effect will imply that male decision-makers have a structural advantage over female decision-makers with regard to the specific covariates, while a negative value indicates a female structural advantage. The same reason holds for the other components in Eqs. (6) and (7). Alternatively, we could have used male group coefficient $\left(\beta_{m}\right)$ and predictor $\left(X_{i m}\right)$ levels as weights to determine gender differences between male and female groups due to levels of the endowment and its return effects, respectively. This alternative method of calculating the decomposition often provides different estimates. ${ }^{7}$

\footnotetext{
5 Equation (7) will hold for a logit model that includes a constant term because the average value of the dependent variable must equal the average value of the predicted probabilities in the sample.

6 Fairlie (2005) expanded a nonlinear equation that performs the decomposition for logit or probit model in a 'twofold' decomposition while Sinning et al. (2008) provided it in a 'threefold' decomposition following Daymont and Andrisani (1984) extension of the B-O decomposition. Thus, we included the third component (interaction effect) in Eq. (7).

7 Oaxaca and Ransom (1994) has suggested to use the reference group which corresponds to the pooled sample of both groups. However, we considered female decision-making household as a reference group for male decision-making and joint decision-making household for female decision-making. Between male and joint comparison, joint decision-makings are a reference group. The decision to choose a reference group in this paper was based on empirical studies on gender and agriculture in Ethiopia and elsewhere. For example, females may be less likely to sell maize not only because they have less access to land but also they have access to land of less quality or to extension advice (World Bank 2014).
} 
Equation (7) provides the contribution of the gender gap in food security due to gender differences in the entire set of included variables; however, identifying the contribution of the gender gap in security due to the gender differences in specific variables is not as straightforward. The contribution of each variable to the gender gap in food security is equal to the change in the average predicted probability from replacing the female group distribution with the male group distribution of that variable while holding the distributions of the other variable constant. ${ }^{8}$ To estimate the contribution of each variable to the gender gap using the nonlinear decomposition method, the sample sizes of two groups must be equal (Fairlie 2005), i.e., one-to-one matching of female and male observations. Thus, we used an equal sample size for two groups to calculate the contributions of individual variables to the gender gap in the probability of being food secure, transitory food insecure, and chronic food insecure.

To decompose the gender gap between groups in any of the identified states of food security (e.g., the proportion of female and male decision-making households who are food-secure, transitory food-insecure, or chronically food-insecure), three binary logit models (one for each category) are used to predict household food security status in a counterfactual process, using the extended versions of the B-O decomposition model.

\section{Materials and Methods}

\subsection{Backgrounds of the Study Area}

The research field for this study is Dawuro zone located in South Nations, Nationalities, and People Regional (SNNPR) state of Ethiopia (Fig. 1). Geographically, Dawuro lies in between $6^{\circ} 35^{\prime}$ to $7^{\circ} 34^{\prime}$ north latitude and $36^{\circ} 04^{\prime}$ to $37^{\circ} 53^{\prime}$ east longitudes. The altitude of Dawuro ranges from 500 to $3000 \mathrm{~m}$ above the sea level. The landscape of Dawuro consists mainly of mountains, plateaus, deep gorges, and lowland plains. Thus, Dawuro exhibits climatic variations from lowland to highland. The climatic variations have enriched Dawuro with a variety of tree species and natural vegetation/forests (Gebre et al. 2019b). The majority of the Dawuro people (91\%) live in rural areas (Negashi 2019), and their livelihood is based on a mixed crop-livestock production system.

Dawuro zone is one of the major crop production areas of the country. The principal crops produced in the zone include ensete (ensete ventricosum), teff (eragrostis tef), maize, sorghum, wheat, barley, coffee, beans, peas, spices, vegetables, and fruits. Dawuro zone has ample potentials for crop production, but their farm productivity is limited because of the inefficient traditional means of production, dependence on natural rainfall, and poor market infrastructures, making the livelihood of farm households stagnant (Abebe 2014). Both male and female farm households ${ }^{9}$ are involved in agricultural activities in the zone;

\footnotetext{
${ }^{8}$ Unlike in the linear case, the independent contribution of one variable depends on the value of the other variable included in the model. This implies that the choice of a variable (the order of switching the distributions) is potentially important in calculating its contribution to the gender gap in food security.

${ }^{9}$ In this study, male farm households are defined as the households in which the major decision-makers are men. Likewise, female farm households are defined as the households in which the major decision-makers are women for their household production and consumption processes. Joint decision-making farm households are defined as the households in which the production and consumption decisions are made equally between male and female family members, in particular between husband and wife, within the household.
} 


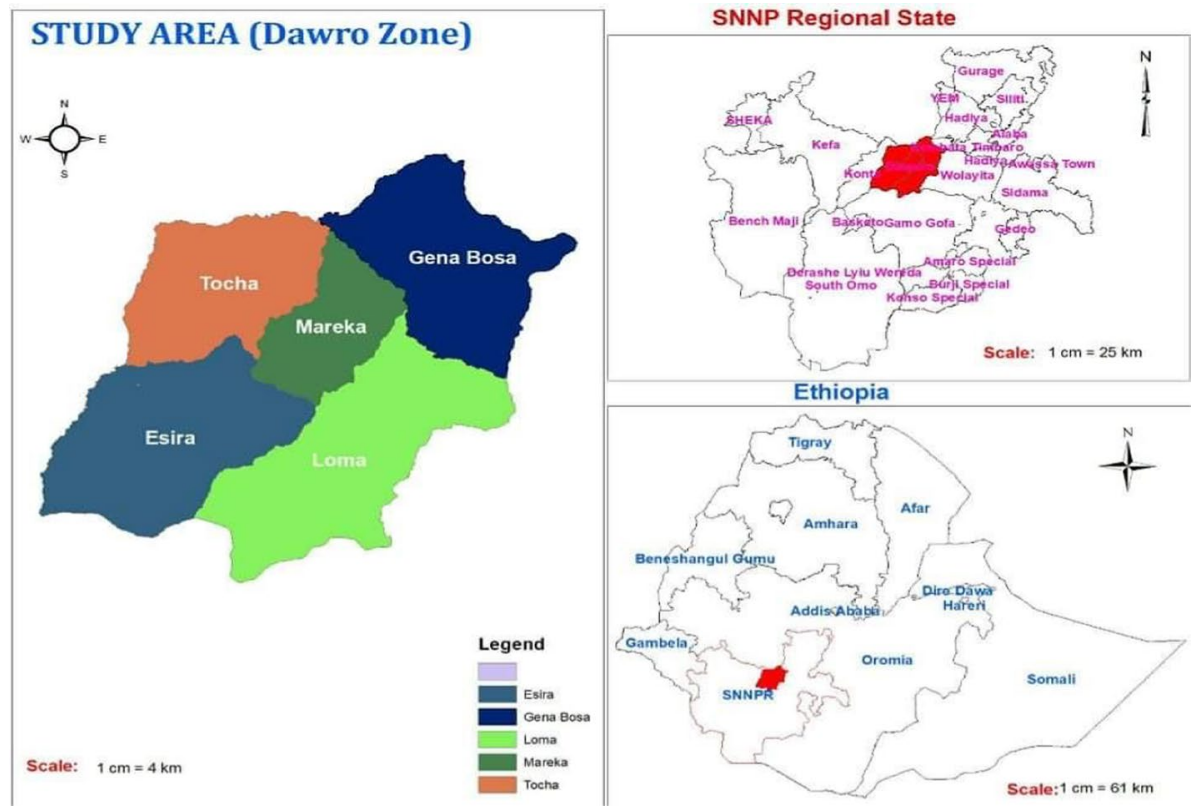

Fig. 1 Map of the study area (Dawuro Zone) in SNNPR, Ethiopia. Source: Authors

however, females are more vulnerable to food poverty due to lack of access to farmland, shortage of farm labour, and/or lack of draft animals for food crop production.

\subsection{Data and Sampling Design}

The data used in this study were collected in 2018 from 560 maize producing farm householdsin Dawuro zone, SNNPR state of Ethiopia. Multi-stage purposive sampling strategies based on probability proportional to size (PPS) ${ }^{10}$ were used to select districts, kebele, ${ }^{11}$ and farm households in the Dawuro zone. First, four districts, namely 'Loma (including Disa), Mareka, Esara, and Tocha (Kachi \& Tarcha zuriya)', were selected based on their maize production potential. Second, 6-8 kebeles were selected from each district, where maize is grown as the major staple food for household consumption and source of income. Third, on an average, 20 maize growing households were selected for a survey from each kebele. Accordingly, a total of 560 smallholder maize producer households were included in the survey. This was done with the assistance of agricultural development (DA) agents ${ }^{12}$ who

\footnotetext{
${ }^{10}$ PPS sampling is a variant of stratified sampling which is used when the sampling is conducted in multiple stages. It can also be called 'unequal probability sampling' because one actually increases the odds that a subject will be chosen in the sample based on its size. The advantage of using this approach is that it helps reduce the standard error and bias by increasing the likelihood that a sampling unit from a larger population will be chosen over a sampling unit from a smaller population, thereby obviating the need for sample weighting (Marenya et al. 2017).

11 In Ethiopia, kebele is the smallest administrative unit followed by Woreda (district).

12 Agricultural development (DA) agents in Ethiopia are also known as 'extension agents' who graduated from the Agricultural Technical and Vocational Education Training (ATVET) College or Agricultural Universities. They work at the kebele level. Three DA agents are assigned to each kebele to provide effective
} 
were in constant contact with the farm households in each kebele. In all sampled households, maize production takes place at the household level, and one or two family members (mostly husband, wife, or adult son(s)) within the household make maize production and consumption decisions either independently or jointly. As per the cultural norm of Dawuro community, a couple (wife and husband) of a household in the study area typically does not have separate maize farms (Gebre et al. 2019a). In each household, the person most responsible for household food crop production (either husband, wife, or an adult son) was selected for the face-to-face interview.

A semi-structured questionnaire was designed and tested to collect a range of information related to household demography, socio-economic features, agricultural production, and food security, including perceptions of household food security status, using experienced and well-trained enumerators under the close supervision of the researchers in the field. The questionnaire also captured some individual, household, and plot-level attributes, as well as institutional arrangements besetting household on-farm management. The individual attributes included age, gender, and education of the household head, and who the decision-maker in the household is. Household features included the amount of available labour and labour division in the household, number of livestock owned, landholding, amount of harvest, and off-farm incomes, among others. Plot characteristics included the size of the plot allocated to maize farming, types of maize varieties used, and kinds of farming practices adopted. Institutional arrangements included access to the market, access to credit service, participation in farmer training, and other logistics.

The survey research also involved data collection for the identification of each respondent household into three gender decision-making categories: male, female, and joint. All the household respondents were asked a total of 20 gender-disaggregated questions (see "Appendix"). The first 12 questions pertained to the ownership of farmland and other farmrelated assets in the households, maize production decisions, and maize production activities such as variety choice, maize farm preparation, planting, fertilizer use, weeding, harvesting, and collection. The remaining 8 questions were related to the decision-making on the amount of maize for allocation between home consumption and sale, the responsible person in the household for maize sale, buyer choice, price decisions, and utilization of money out of maize sales. All responses indicated that decisions about maize production, consumption, and selling in the market were made by either men or women, or together. In addition to a key household informant, an additional family member was separately asked some supplemental questions; for example, they were asked who makes decisions on maize production and consumption. This is because the information collected from a single respondent may not accurately describe their intra-household gender dynamics. In a few cases, men and women from the same household gave different answers to the same questions. In such cases, both respondents were jointly asked who makes decisions on maize production and consumption in the household. In doing so, they reached a consensus. Finally, the collected responses were clustered into the three household decision-making categories-male, female, or joint. In doing so, the principal component analysis ${ }^{13}$ was used to group the households into the three gender categories.

Footnote 12 (continued)

extension services for farmers in the areas of crop and livestock production and natural resource management (Gebre et al., 2019a).

13 Principal Component Analysis is a dimensionality-reduction method that is often used to reduce the dimensionality of large data sets, by transforming a large set of variables into a smaller one which still contains most of the information of the large set. 


\section{Results and Discussion}

\subsection{Descriptive Result}

Table 1 presents descriptions of the variables used in the econometric model estimation as well as summary statistics and statistical significance tests with regard to the gender of the decision-makers. Regarding the food security status of the sampled households, $41 \%$ are food-secure, while $35 \%$ and $24 \%$ are transitory food-insecure and chronically food-insecure households, respectively. These results indicate that about $41 \%$ and $59 \%$ of the total sampled households are food-secure and food-insecure, respectively. Our results are higher than the findings reported by WFP and CSA (2019) in a comprehensive food security and vulnerability study using national-level data collected in Ethiopia in 2015/2016. They used objective measures of food security and reported that about $20.5 \%$ of households in Ethiopia (22.7\% rural and $13.9 \%$ urban) were estimated to be food-insecure in 2016. According to them, his result was directly relevant to approximately 26 million food-insecure people. However, they noted that the number of food-insecure people could have been much higher, had food assistance not been provided to around 18 million people through emergency food assistance and productive safety net programs. On the other hand, our results are lower than the findings reported by Mota et al. (2019) in the Wolaita zone, southern Ethiopia. They used subjective measures of food security and found that about $71.6 \%$ and $28.4 \%$ of farm households are food-insecure and food-secure, respectively.

Of the male decision-making households, $46 \%$ are food-secure, $34 \%$ transitory foodinsecure, and $20 \%$ chronically food-insecure. Of the female decision-making households, $34 \%, 40 \%$, and $26 \%$ are food-secure, transitory food-insecure, and chronically food-insecure households, while the joint decision-making households constitute 43\%,29\%, and $28 \%$, respectively. Without indicating any causal relationship, the results show that there are significant gender differences between male and female decision-making households in all states of food security. However, between male and joint decision-making, a significant difference is found among chronically food-insecure households. The results also show that there are significant differences between female and joint decision-making in the categories of food-secure and transitory food-insecure households. The higher proportion of female decision-making households in the transitory food-insecure category would be an indication of their vulnerability to the weather and climate variability in the study area. The previous study by Tibesigwa et al. (2015) noted that climate and weather variability in subSaharan Africa disproportionately renders female-headed households food-insecure.

Regarding household headship, about $73 \%$ of the sampled households were headed by males, with females heading $27 \%$. In terms of gender-based decision-making, about $43 \%, 21 \%$, and $36 \%$ were male, female, and joint decision-making households, respectively. Among male-headed households, $57 \%$ and $41 \%$ are male and joint decision-makers, respectively, while the remaining $2 \%$ are female decision-makers. Among female-headed households, $72 \%$ and $23 \%$ are female and joint decision-makers, respectively, while the remaining 5\% are male decision-making households. This indicates that females in maleheaded households and males in female-headed households independently or jointly make decisions on crop production and food consumption in the study area. This result is consistent with Aregu et al. (2011) and Doss (2015). It suggests that the studies that use household headship as the sole gender criteria would fail to capture a substantial part of gender heterogeneity in decision-making for agricultural production and consumption in Ethiopia. It is noted, however, that either male or female, if not both, are the dominant 


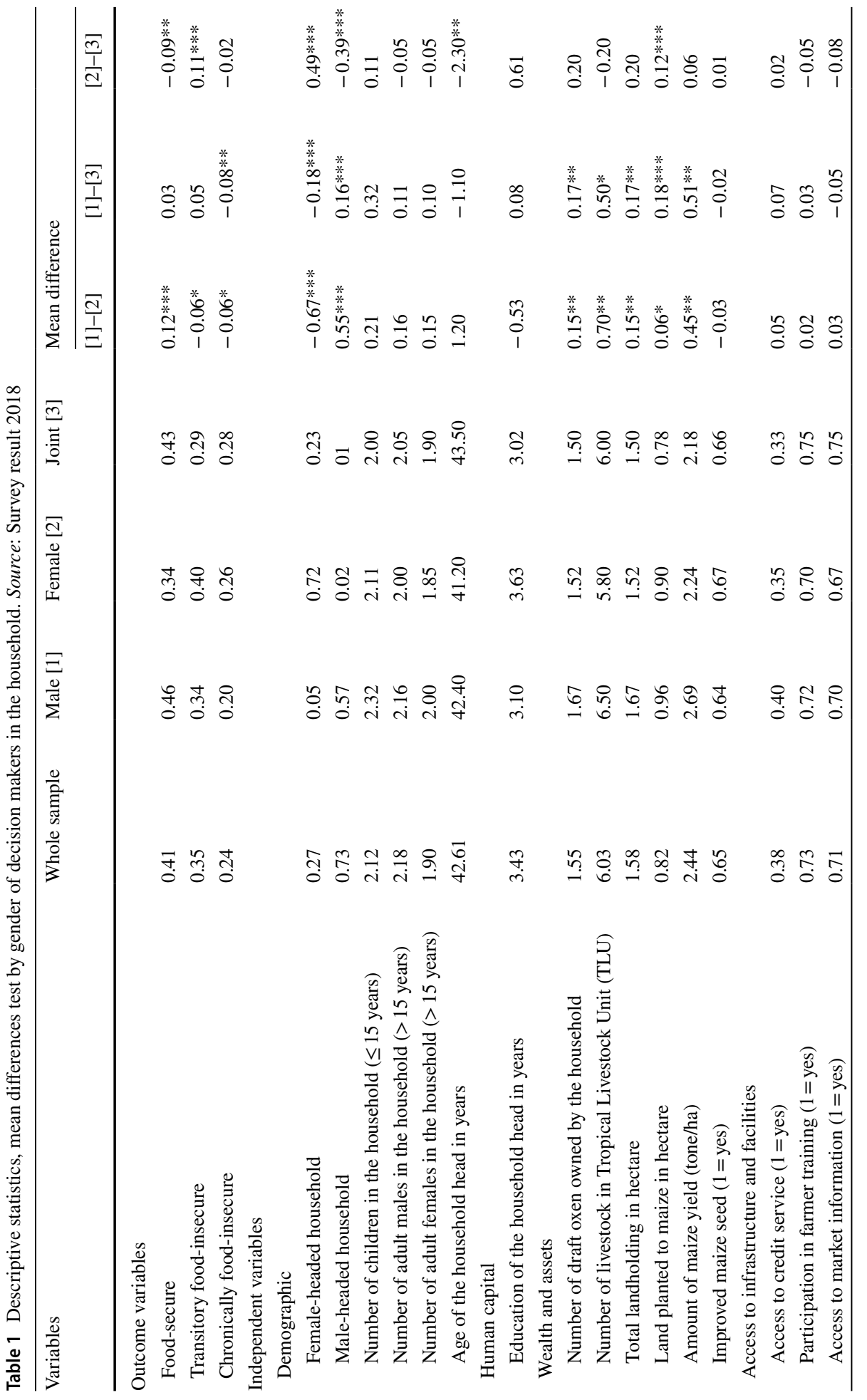




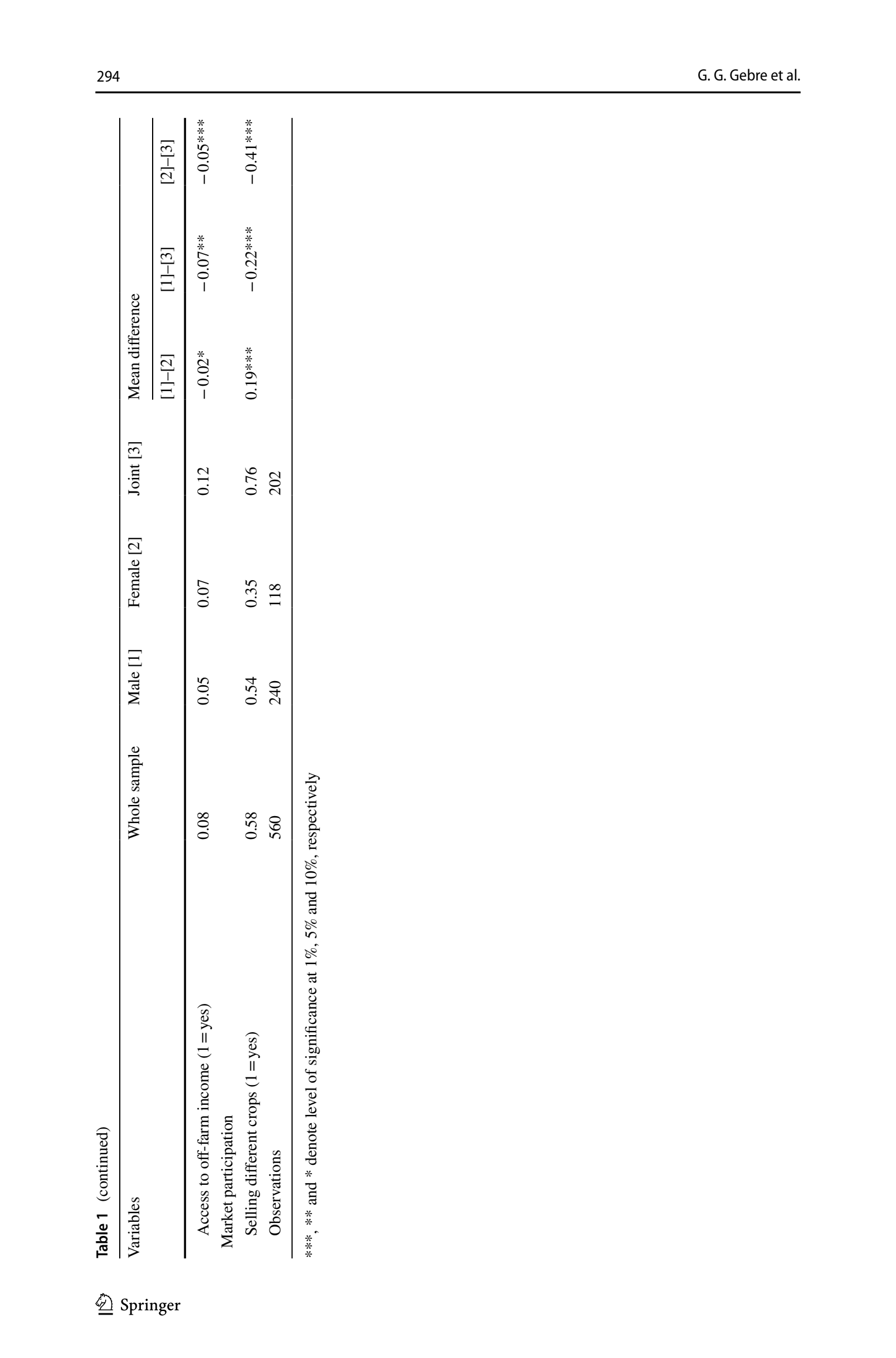


decision-makers for crop production and its intrahousehold allocation for consumption in male and female-headed households, respectively. This point might be linked to the social status of the major household decision-maker as the head of household, who tends to have greater asset ownership than other family members, and who accordingly commands prominent decision-making power in the household (Deere et al. 2009).

Even without indicating any causal relationship, the average number of both 'livestock' (measured in TLU) ${ }^{14}$ and 'oxen' owned by male decision-making households are significantly higher than those of female and joint decision-making households. Moreover, the average total size of landholding, the average size of maize-planted land, and the average maize yield are significantly higher for male decision-making households than female and joint decision-making households. These results indicate that male decision-making households have a greater household asset holding than female and joint decision-making households. Meanwhile, joint decision-making households rely more on off-farm incomes and selling different crops than male and female decision-making households. This indicates that men and women within joint decision-making households engage more in off-farm income-generating activities (Aregu et al. 2011) and that they grow a more diverse set of crops per plot as part of their livelihood diversification strategies than individual decisionmaking households. These might be linked to joint decision-makers' smaller landholding status compared to the cases of individual decision-makers.

\subsection{Econometric Results}

\subsubsection{Factors Affecting Gender Differences in Food Security}

The results of the factors affecting the food security of the surveyed farm households are presented in Table 2. We estimated pooled and separate (gender-based decision-making) samples in order to examine the gender effects on the probability of household food security status. In both estimations, the model is significant at $1 \%$ level, meaning the explanatory variables taken together explain the food security status of the sampled households. In the pooled sample estimation, we included the sex of female and joint decision-makers as gender indicator variables with male decision-makers treated as a reference category. This setting helps examine whether there is are any significant gender differences in the food security status of the households after controlling other covariates. Since the coefficients of the ordered probit do not represent the magnitude of the effects of the explanatory variables, the marginal effects solely are discussed. These marginal effects are interpreted based on the sign and category.

The pooled sample estimates show that the female decision-maker dummy variable is negatively associated with the food-secure category and positively associated with the transitory and chronically food-insecure category compared to the male decision-making households. The joint decision-makers dummy is significantly and positively associated with the probability of being chronically food-insecure compared to the male decision-makers. These results suggest that controlling other covariates, the placement of the household into any of the three food security states (i.e., food-secure, transitory foodinsecure, or chronically food-insecure) is significantly explained by the gender of female

\footnotetext{
14 Tropical Livestock Units refers to livestock numbers converted to a common unit (Harvest Choice 2015). The conversion factors adopted are: cattle $=0.7$, sheep $=0.1$, goats $=0.1$, pigs $=0.2$, and chicken $=0.01$.
} 


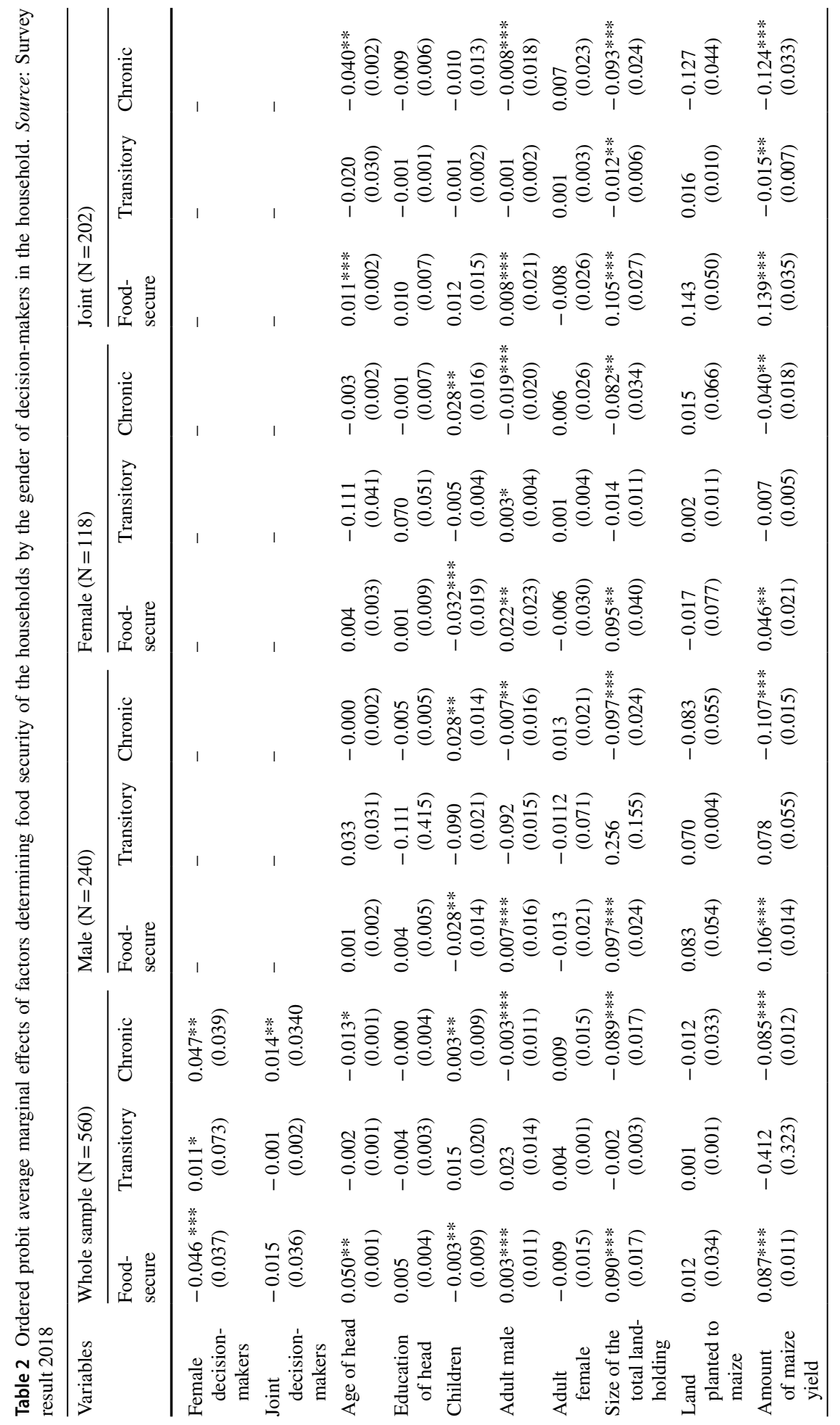




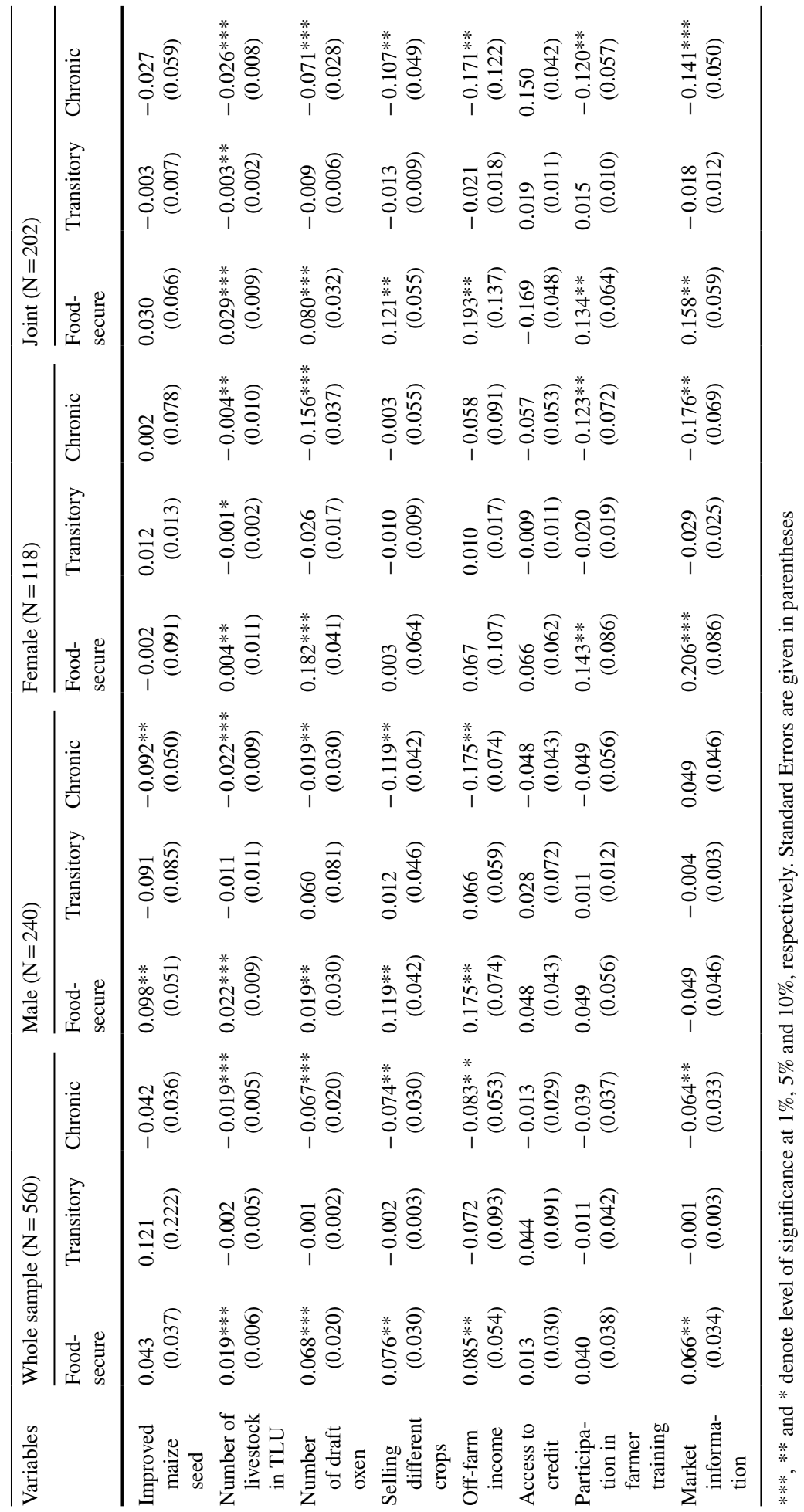


decision-makers in all categories of food security state, and by the gender of joint decisionmakers in the household. This might be linked to a lower wealth status of female and joint decision-making households as observed in Table 1.

An increase in the age of the household head by 1 year increases the probability of a household being in the food-secure category by 0.05 and decreases the probability of being in the chronic food-insecure category by 0.013 . As age is a proxy for farming experience (Mango et al. 2014), a rural household's knowledge of food security issues will increase as their heads get older and more experienced in farming. This result is in line with studies by Bogale and Shimelis (2009) and Mitiku et al. (2012) in Eastern and Southern Ethiopia, respectively. The result would be related to the cause that as farm households acquire more experience in farming operations, they become more risk-averse, engage in better planning, diversify productive activities, accumulate wealth, and consequently have a better chance to become food-secure. Other covariates included in the pooled estimation include the number of adult males in the household, size of household landholding, maize yield, number of livestock in TLU, number of draft oxen, selling of different crops, access to off-farm income, and market information. These are significantly and positively associated with the probability of households being in the food-secure category while decreasing the probability that the households fall in the chronically food-insecure category. Meanwhile, the number of children in the household are negatively associated with the food-secure category and positively associated with the chronic food-insecure category in the male and female decision-making households.

The results of the regression based on the gender of decision-makers show that an increase in the age of the household head by 1 year increases the probability of joint decision-making households entering the food-secure category by $1.1 \%$ while decreasing the probability of falling into the chronically food-insecure category by $4.0 \%$. A plausible explanation for these results is that joint decision-making households with older household heads could be more experienced in farming operations; hence, they are more cautious about the use of risk-prone agricultural technologies, they grow different crops on a certain area, and are more successful at accumulating wealth. Along this line of explanation, a previous study by Gebre et al. (2019a) identified the negative relationship between the age of the head and adoption of the improved maize varieties in joint decision-making households. This finding was arguably linked to the lack of less experienced farmers to reduce risks associated with the use of improved maize varieties that are vulnerable to the harsh environmental conditions of a dry spell, during which insect pests and disease spread. In a similar vein, Gebre et al. (2020) identified a positive relationship between the age of the head and being a net seller in the market among the joint decision-making farm households in southern Ethiopia.

An increase in the number of children in male and female decision-making households significantly decreases the probability of these households being positioned in the foodsecure category while increasing the probability of them falling into the chronically foodinsecure category. This result could be linked to the number of dependent family members in the household. The dependency burden within the household is a strong predictor of household-level food security status (Mutisya et al. 2016). It increases the need for household food consumption, putting more pressure on the household to fall into food-insecurity.

An increase in the number of adult males in the male and joint decision-making households significantly increases the probability of being in the food-secure category and decreases the probability of falling into the chronic food-insecure category. Regarding female decision-making households, an increase in the number of adult males increases the probability of coming into the food-secure and transitory food-insecure categories, and it 
decreases the probability of falling into the chronically food-insecure category. An increase in adult males in the agrarian household is tantamount to an increase in the availability of male labour for physically intensive agronomic activities such as plowing with oxen, planting, weeding, harvesting, and collection. In particular, plowing with oxen and planting are considered male tasks in the study area due to the relatively more intensive physical labour required than other tasks. Thus, the results suggest that a farm household with a larger pool of male family labour is more likely to be food-secure due to their greater capability to produce food. This result is in line with a study by Mango et al. (2014). Further, the result seems to indicate that male and joint decision-making households have a greater capability to utilize male labour for farming activities than female decision-making households.

The size of the total landholding is shown to have a positive effect on the probability that all types (male, female, and joint) of households enter the food-secure category, as well as a negative effect on the probability to fall into the chronic food-insecure category. A possible explanation for these results is that households with a larger size of landholding could have a larger production and hence are less prone to the risk of food shortage. An increase in the amount of maize yield significantly increases the probability that households of all the three gender categories fall into the food-secure category, while it decreases the probability that they fall into the chronically food-insecure category. This result would be because households with higher maize productivity could produce more food per plot of land for home consumption than those with lower maize productivity.

The use of improved maize varieties (IMVs) significantly increases the probability of male decision-making households entering the food-secure category by $9.8 \%$ and decreases the possibility of entering the chronically food-insecure category by $9.2 \%$, compared to traditional maize variety users in the same category of households. For female and joint decision-making households, the use of improved maize varieties is not significantly associated with their food security status.

An increase in the number of livestock in TLU unit increases the probability that all male, female, and joint decision-making households enter the food-secure category. This result indicates that possession of livestock is crucial to ensure the food security of agrarian households. In the study area, the number of livestock owned by a household is an indicator of its socio-economic standing. They get milk and other processed products and sell them for cash to meet their subsistence and other needs. Along with fertilizer, milk can also be a vital input for crop production. Livestock is a critical asset for liquidity as farm households sell them to buy food in confronting a food shortage. It is also critical as an asset for self-insurance to prepare for the food-scarce moment even when they have sufficient food for the present. An increase in the number of draft oxen owned by a farm household of any gender category significantly increases the probability that it enters the food-secure category while decreasing the probability of falling into the chronically food-insecure category. A possible explanation for this result is that farm households in the study area exclusively use ox-plowing for crop production. Accordingly, oxen and other livestock are not interchangeable for farming activities in the study area. Oxen help farm households to meet their food need by providing animal labour for cultivation and hence to generate income associated with sales of produced crops.

In the case of male and joint decision-making households, selling different crops in the market helps them significantly increase the probability of entering the food-secure category while decreasing the probability of falling into the chronically food-insecure category. This result may indicate that men and joint decision-making households who grow diversified crops have a better chance of ensuring food security by fulfilling the nutritional requirements of their family members through growing and selling multiple crops. The 
positive relationship between the food-secure category and sales of multiple crops is in line with findings by Nyikahadzoi et al. (2012). Regarding male and joint decision-making households, access to off-farm income significantly increases the probability of entering the food-secure category while decreasing the probability of falling into the chronically food-insecure category. Participation in farmer training and access to market information significantly increases the probability of female and joint decision-making households falling into the food-secure category while decreasing the probability of falling into the chronic food-insecure category.

\subsubsection{Gender Gaps in Food Security}

This section presents the results from the application of nonlinear B-O decomposition techniques for gender-based decision-making households. A set of nonlinear decomposition was run separately for the gendered food security gap between male and female, male and joint, and female and joint decision-making households (Table 1). Decomposition was performed for all the three categorical states of food security.

Table 3 presents the decomposition results of gendered food security gaps between male and female decision-making households. The results show that there is a significant gender gap between male and female decision-making groups in all the food security categories, with the food-secure category showing a much higher magnitude of significance than the other categories. The actual mean probability of being in the food-secure category among female decision-making households is $12.1 \%$ lower than that among male decision-making households. Meanwhile, the mean probability of being in the transitory and chronic foodinsecure categories among females is $6.0 \%$ and $6.1 \%$ higher, respectively, than that among males. The gender gap between males and females in the food-secure category is explained by the endowment and coefficient (return) effects while that in the transitory and chronic food-insecure categories are explained by the coefficient effect.

The results of aggregate decomposition in the food-secure category suggest that, if females had the same amount of resources as males, their probability of taking the foodsecure position would increase by $4.6 \%$ (cf., endowment effect of 0.046 ). If females had the same returns from their resources (i.e., the covariates included in the regression model) as males, their probability of being in the food-secure category would increase by $11.6 \%$ (cf., coefficient effect of 0.116 ). About $77.3 \%$ of the 'total gap in the foodsecure group' (i.e., $12.1 \%$ higher for males than females, with $1 \%>$ significance) is explained by the return effect while the rest of the gap is attributed to the endowment effect $(30.67 \%)$ and the interaction effect $(8.00 \%)$. These results indicate that the magnitude of returns effect on the gender gap between male and female decision-makers is about 2.5 times higher than the endowments effect in the food-secure position.

The detailed decomposition results indicating contributions of individual covariates to the gap show that the number of adult males, size of the total landholding, number of oxen, off-farm income, and participation in training significantly contribute to the endowment portions of the gap, whereas education levels of the head, size of the total landholding, maize yield and access to the market information contribute to the coefficient portions of the gap. The results suggest that females have the disadvantage in endowment levels of the number of adult males, the size of the landholding, oxen owned, and participation in training, while they would have an advantage in access to off-farm incomes than their male counterparts in the food-secure position. Female decision-making households would benefit from returns to their household head's education 


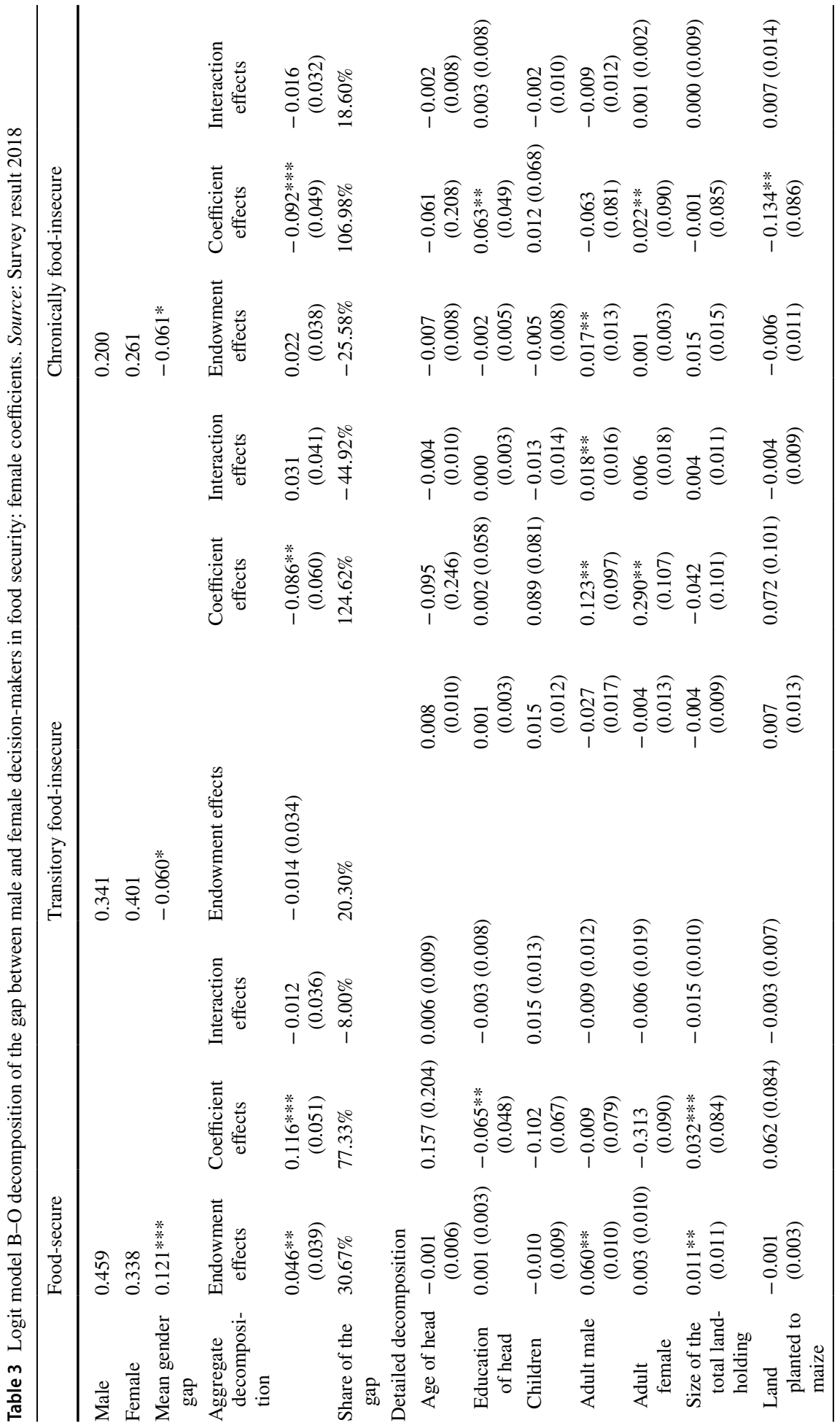




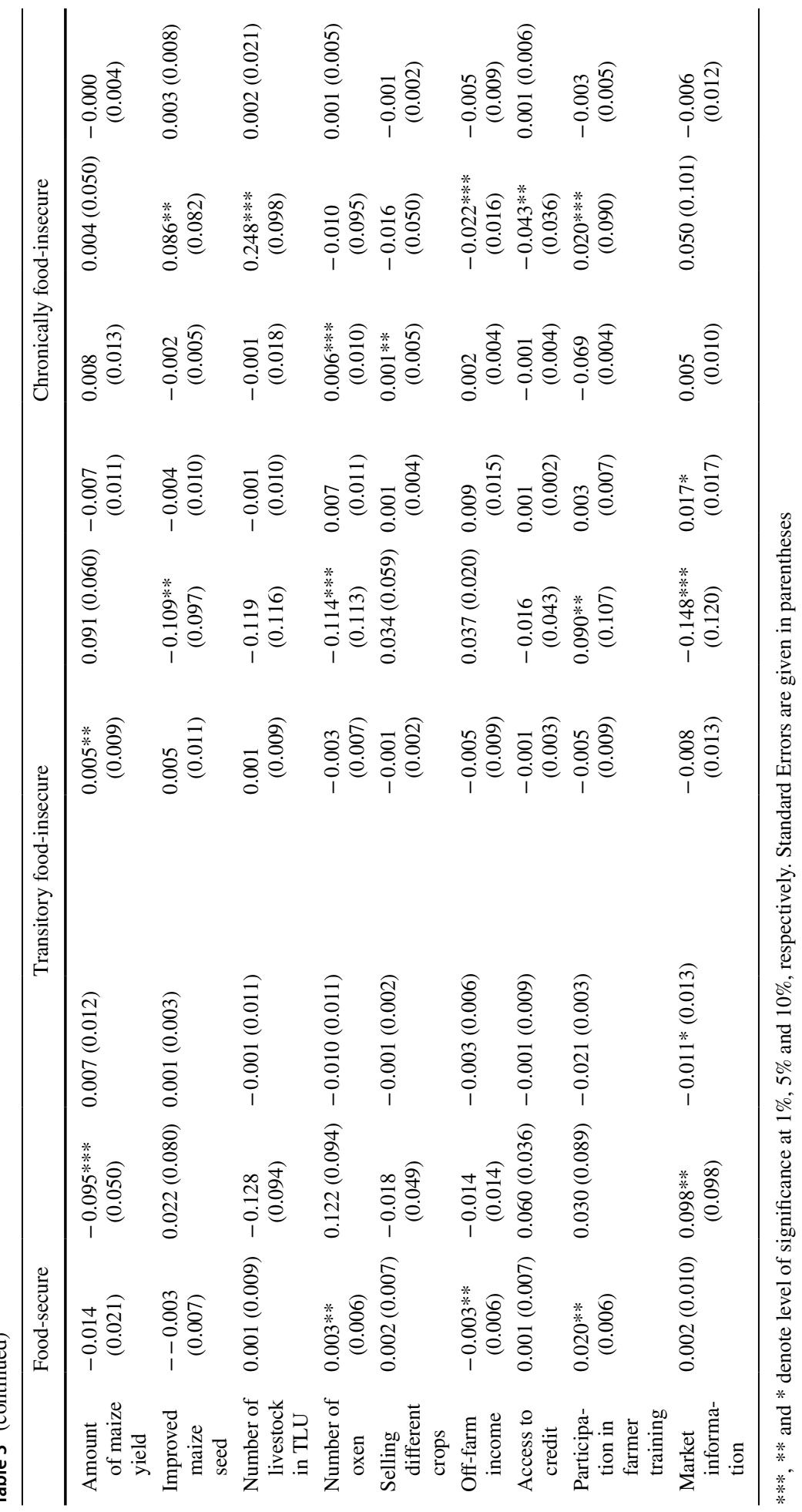


and maize yield more than male decision-making households taking the food-secure position. However, their benefits from the size of the landholding and access to market information would be less than the male decision-makers.

The results of aggregate decomposition in the transitory food-insecure category indicate that if females had the same return as males, their probability of falling into the transitionary food-insecure position would decrease by $8.6 \%$. Of the total gap in this position (i.e., $6.0 \%$ higher for females than males, with $10 \%>$ significance), about $124.6 \%$ is explained by the coefficient effect, with the rest explained by the endowment effect $(20.30 \%)$ as well as the interaction effect $(44.92 \%)$. The detailed results suggest that returns from the number of adult males and adult females and participation in farmer training significantly contribute to a widening of the total gap. Meanwhile, the use of improved maize variety (IMVs), the number of oxen owned, and access to market information contribute to closing the return effect portion of the gap in the transitory food-insecure position.

The results of the chronic food-insecure category indicate that with the same level of returns as males, the probability of the females falling into the chronic food-insecure status would significantly decrease by $9.2 \%$ from the total gap (i.e., $6.1 \%$ higher for females than males, with $10 \%>$ significance). The detailed results suggest that female decision-making households have more structural disadvantages in returns associated with their head's education, number of adult females in their household, use of IMVs, number of livestock units, and participation in farmer training; however, they have a more structural advantage in returns related to maize-planted land and off-farm incomes, compared to male decisionmaking households in the chronic food-insecure position.

Table 4 presents the decomposition results of gendered food security gaps between male and joint decision-making households. The average gaps are not significant in the food-secure nor transitory food-insecure categories; however, it is significant in the chronic food-insecure category ( $8.0 \%$ higher for joint than males, with $10 \%>$ significance), which is mainly explained by the coefficient and interaction effects. The results largely suggest that if joint decision-making households had males' resource return, their average probability of taking the chronically food-insecure position would decrease by $8.6 \%$, helping to close the existing gender gap in the chronic food-insecure category. The positive and significant interaction effect in the chronically food-insecure category suggests that the return effect accounts for over $75 \%$ of the gap between male and joint decision-making households. Overall, about $153.6 \%$ of the total gap in the chronic food-insecure position is explained by the coefficient effect while the rest of the gap is explained by the endowment (23.21\%) and interaction (76.78\%) effects.

The detailed decomposition results indicate that joint decision-making households would benefit from the returns to the number of adult male labourers, use of IMVs, the number of livestock units, and access to market information, less than the male decision-making households of the chronically food-insecure position; however, their benefit from the returns to the size of the landholding, selling different crops, and access to credit service would be more than the male decision-makers.

Table 5 provides the decomposition results of gendered food security gaps between female and joint decision-making households. The average gaps are significant in the food-secure position (i.e., 9.0\% lower for females than joint, with 5\%> significance) and the transitory food-insecure position (i.e., 10.9\% higher for females than joint, with $1 \%>$ significance), while the gap is not significant in the chronically food-insecure position. The average gap in the food-secure position is significantly explained by the effect of the return, while that in the transitory food-insecure position is significantly explained by the endowment and return effects. 


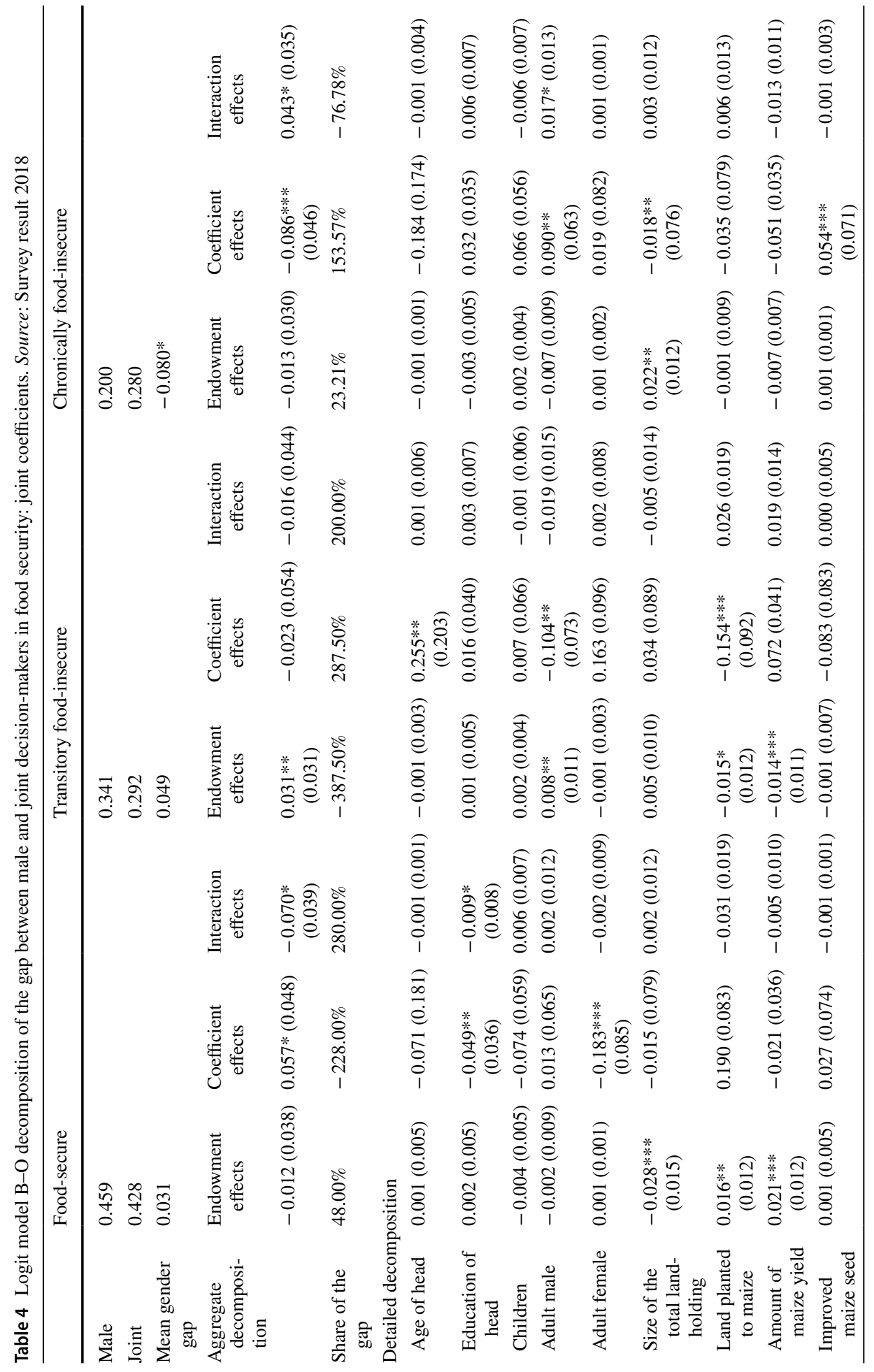




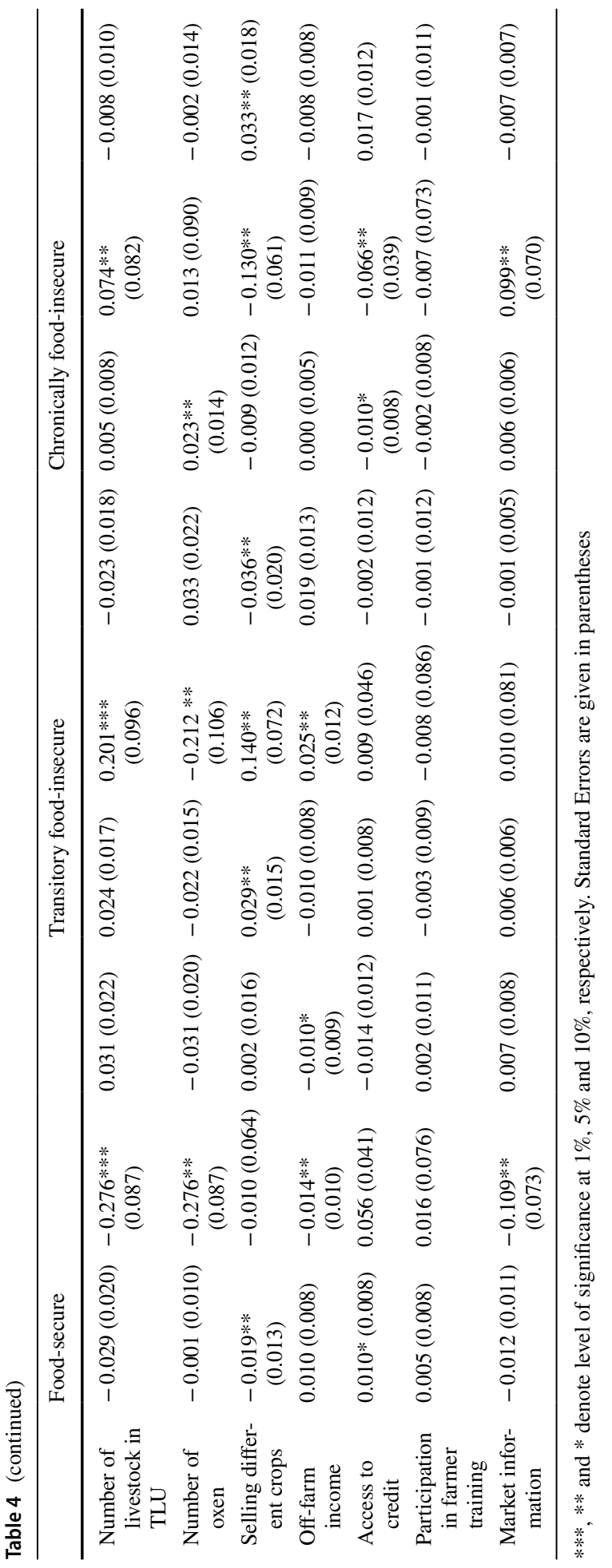


The aggregate decomposition results in the food-secure position suggest that if the joint decision-making households had the female's resource return, their average probability of taking the food-secure position would be decreased by $10.1 \%$, thus even reversing the existing gender gap (9.0\%) in the food-secure position, to the advantage of joint decision-making households. This indicates that in aggregate, joint decision-makers would benefit from their resource return more than female decision-makers. The detailed decomposition results in the food-secure position indicate that joint decision-makers would obtain the returns to the age of the household head, size of the landholding, oxen owned, training, access to credit, and market information, more than female decision-makers taking the food-secure position; however, they would receive returns associated with the number of adult males, adult females, and the size of land for maize, less than the females.

The aggregate results in the transitory food-insecure position imply that compared to female decision-makers, joint decision-makers would have a disadvantage from both their resource endowments and their associated returns. If joint decision-makers had as many resources as females, their average probability of taking the transitory food-insecure position would increase by $1.4 \%$. Similarly, if joint decision-makers had females' resource returns, the probability of taking the transitory food-insecure position would increase by $10.5 \%$. The detailed decomposition results in the transitory food-insecure position indicate that maize yield, number of oxen owned, and market information would largely contribute to closing the portion of the gap emanating from the endowment effect while selling different crops would contribute to widening the portions of the gap derived from the endowment effect. On the other hand, returns from the age of the household head and number of livestock units owned by the household would contribute to widening the portion of the gap emanating from the coefficient effect, while the number of adult males, the number of adult females, maizeplanted land, and participation in training would contribute to closing the coefficient portion of the gap in the transitory food-insecure position.

\section{Conclusion and Policy Implications}

There are numerous studies on the interlinkage between gender and food security. However, most of these studies use sex of the household head as a gender indicator, which ends up dismissing the contributions of males in female-headed households and females in male-headed households. They do not consider the joint contributions by male and female family members to their household food security either. As a result, those studies fail to capture complex gender heterogeneity associated with the food security statuses of agrarian households. In addition, most of them sort studied households into only two categories of food security status: food-secure and food-insecure. Such a dichotomy leads investigators to neglect the prevalence of more nuanced patterns of food insecurity among the households. Moreover, they apply regression models that predict gender differences in food security from the coefficient/intercept effect of binary gender variable, which fails to recognize the interaction between the gender and other covariates included in the model.

Using primary data collected from Dawuro zone, southern Ethiopia, the present study has examined gender-differentiated household food security statuses by dividing the sampled farm households into three gender-based decision-making categories: male, female, and joint. Households in each decision-making category are placed into either food-secure, transitory food-insecure, or chronically food-insecure categories based on their status of 


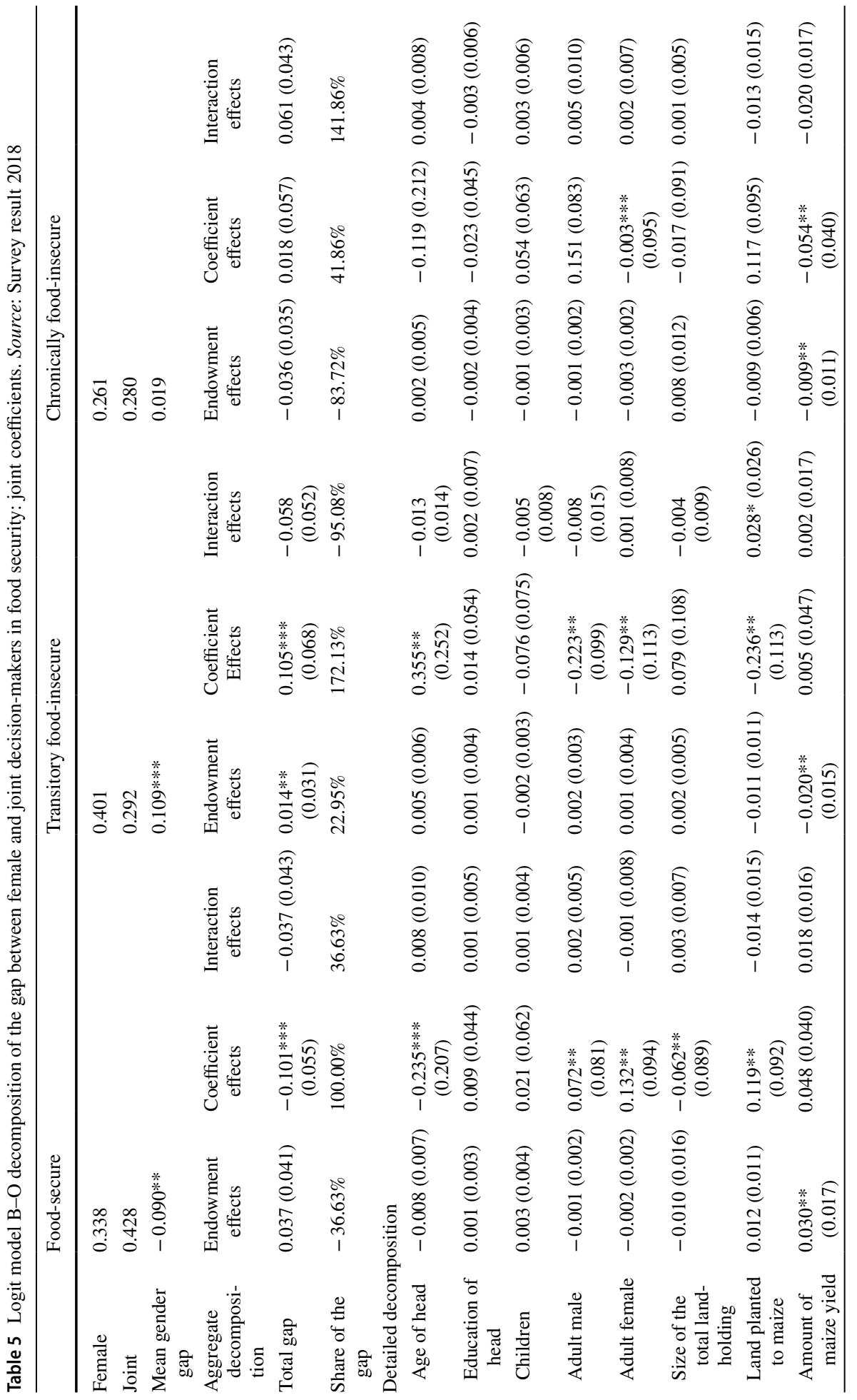




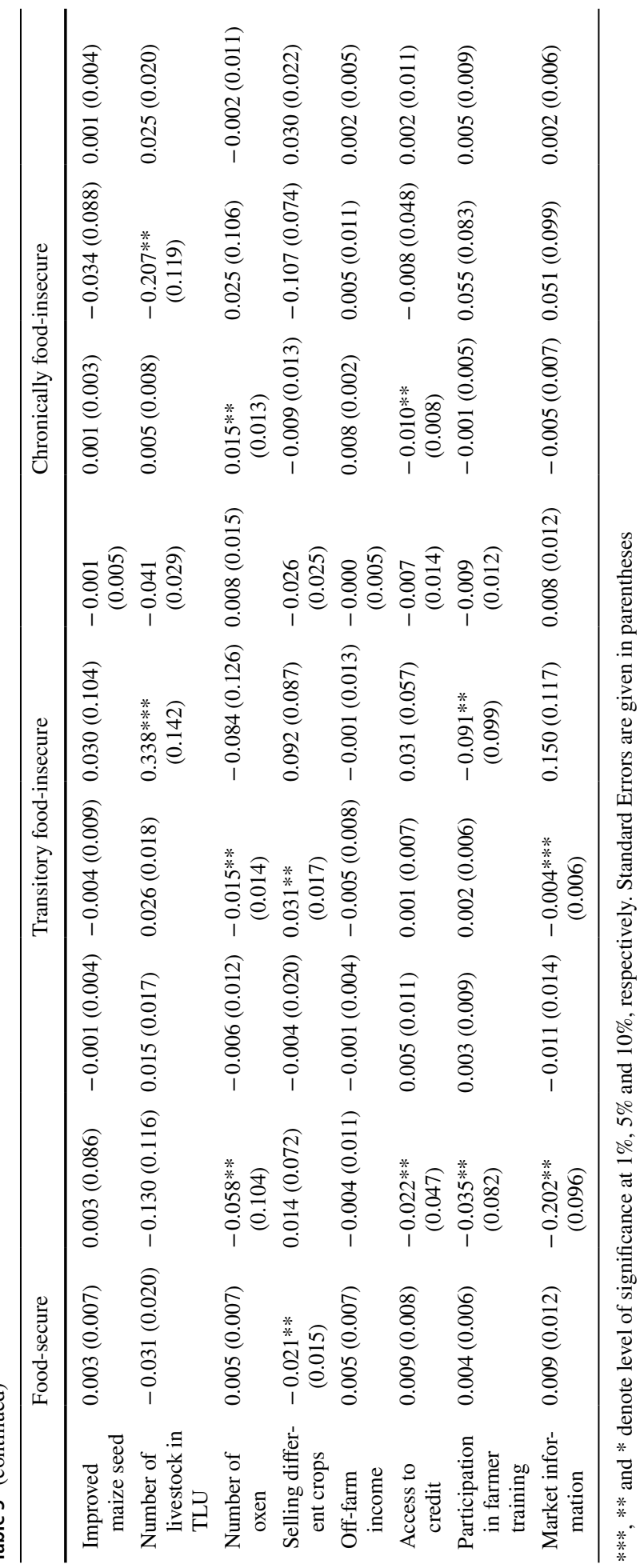


food security. The study used ordered probit and nonlinear Blinder-Oaxaca decomposition methods to analyze gender gaps in food security.

Through an ordered probit regression, the study identified significant gender gaps in the probability of food security among the gender-based decision-making households. The results of the whole sample analysis suggest that controlling other covariates and significant household differences in food security statuses are explained by the sex of female decision-makers in all categories of food security statuses, as well as by the sex of the joint decision-makers in the chronically food-insecure category, given that male decision-making households are held as the base category for comparison. These results might be linked to the female and joint decision-making households' lower levels of resource availability as we observed from the descriptive results.

The nonlinear $\mathrm{B}-\mathrm{O}$ decomposition of this study revealed significant gender gaps between male and female decision-making households in all three food security categories $(1 \%>$ significance for food-secure, $10 \%>$ significance for transitory food-insecure, and $10 \%>$ significance for chronically food-insecure). The average gap between males and females in the food-secure category is significantly explained by the endowment and coefficient effects while that in the transitory and chronic food-insecure categories is explained by the return effect. The average gap between male and joint decision-makers is not significant in the food-secure nor transitory food-insecure categories; however, it is significant in the chronic food-insecure category $(10 \%>$ significance), which is mainly explained by the coefficient and interaction effects. The gap in the food-secure category is largely explained by the return effect, while that in the transitory food-insecure position is explained by the endowment and return effects. The average gap between female and joint decision-makers is significant in the food-secure category $(5 \%>$ significance) and the transitory food-insecure category $(1 \%>$ significance), while the gap is not significant in the chronically foodinsecure category. The average gap in the food-secure category is significantly explained by the return effect while that in the transitory food-insecure category is significantly explained by the endowment and return effects.

Given these results, it is proposed that policies not only ensure equal levels of household resources but also help to build the capacity of male, female, and joint decision-making households in the transitory and chronic food-insecure situations so as to improve their food security status. The priority should be given to female and joint decision-making households as they consist of higher proportions of transitory and chronically food-insecure households in the study area.

Acknowledgements We would like to express our sincere gratitude to the International Maize and Wheat Improvement Center (CIMMYT) for supporting our study through the Stress Tolerant Maize for Africa (STMA) project, which is funded by the Bill and Melinda Gates Foundation (Grant No. OPP1134248).

\section{Compliance with Ethical Standards}

Conflict of interest All authors have not conflict of interest on this paper.

Open Access This article is licensed under a Creative Commons Attribution 4.0 International License, which permits use, sharing, adaptation, distribution and reproduction in any medium or format, as long as you give appropriate credit to the original author(s) and the source, provide a link to the Creative Commons licence, and indicate if changes were made. The images or other third party material in this article are included in the article's Creative Commons licence, unless indicated otherwise in a credit line to the material. If material is not included in the article's Creative Commons licence and your intended use is not permitted by statutory regulation or exceeds the permitted use, you will need to obtain permission directly from the copyright holder. To view a copy of this licence, visit http://creativecommons.org/licenses/by/4.0/. 


\section{Appendix}

Questionaries' used to cluster households into male, female and joint decision-making groups. Household decision-making and labor division for maize production, consumption and marketing in 2018.

\begin{tabular}{lll}
\hline & Questions & Responses \\
\cline { 2 - 2 } & & Men Women Both \\
\hline 1 & Who in the household owns maize farmland? \\
3 & Who in the household owns farm equipment? \\
4 & Who in the household owns the crop produce? \\
5 & Who in the household controls maize farmland? \\
6 & Who in the household makes decisions on fertilizer use? \\
7 & Who in the household makes decisions on improved maize seed to use? \\
8 & Who in the household prepares land for maize production? \\
9 & Who in the household plants maize on the farmland? \\
10 & Who in the household weed maize farm? \\
11 & Who in the household harvests maize? \\
12 & Who in the household collects the harvested maize to store? \\
13 & Who in the household made the decision on amount of maize to consume at \\
14 & home? \\
15 & Who in the household made the decision to sell the maize? \\
16 & Who in the household decides when to sell? \\
17 & Who in the household transports the produce to the market? \\
18 & Who in the household sells maize in the market? \\
19 & Who in the household makes decisions to choose buyers? \\
20 & Who in the household makes decision on the use of money obtained from \\
\hline & maize sale?
\end{tabular}

\section{References}

Abebe, Z. T. (2014). The potentials of local institutions for sustainable rural livelihoods: The case of farming households in Dawuro zone, Ethiopia. Public Policy and Administration Review, 2(2), 95-129.

Agarwal, B. (2015). Food security, productivity, and gender inequality. In R. J. Herring (Ed.), The Oxford handbook of food, politics and society. Oxford: Oxford University Press.

Aguilar, A., Carranza, E., Goldstein, M., Kilic, T., \& Oseni, G. (2015). Decomposition of gender differentials in agricultural productivity in Ethiopia. Agricultural Economics, 46(3), 311-334.

Angner, E. (2010). Subjective well-being. Journal of Socioeconomics, 39, 361-368.

Aregu, L., Puskur, R., \& Bishop-Sambrook, C. (2011). The role of gender in crop value chain in Ethiopia. Paper presented at the Gender and Market Oriented Agriculture (AgriGender 2011) Workshop, Addis Ababa, Ethiopia, 31st January-2nd February 2011. Nairobi, Kenya: ILRI.

Aryal, J. P., Mottaleb, K. A., \& Rahut, D. B. (2018). Untangling gender differentiated food security gaps in Bhutan: An application of exogenous switching treatment regression. Review of Development Economics, 00, 1-21. 
Asian Development Bank (ADB). (2013). Gender equality and food security: Women's empowerment as a tool against hunger. Mandaluyong City, Philippines. https://www.adb.org/sites/default/files/publicatio n/30315/gender-equality-and-food-security.pdf.

Behrman, J. A., Meinzen-Dick, R., \& Quisumbing, A. R. (2014). Understanding gender and culture in agriculture: The role of qualitative and quantitative approaches. In A. R. Quisumbing, R. Meinzen Dick, T. L. Raney, A. Croppenstedt, J. A. Behrman, \& A. Peterman (Eds.), Gender in agriculture: Closing the knowledge gap (pp. 31-54). Dordrecht: Springer.

Blinder, A. (1973). Wage discrimination: Reduced form and structural estimates. The Journal of Human Resources, 8, 436-455. https://doi.org/10.2307/144855.

Bogale, A., \& Shimelis, A. (2009). Household-level determinants of food insecurity in rural areas of Dire and Dawa, Eastern Ethiopia. African Journal of Food, Agriculture, Nutrition and Development, 9(9), 1914-1926.

Broussard, H. N. (2019). What explains gender differences in food insecurity? Food Policy, V(83), 180-194.

Central Statistical Agency (CSA) of Ethiopia. (2019). Agricultural sample survey 2018/19 (2011 E.C.) report on area and production of major crops (Vol. I). Private Peasant Holdings, Meher Season.

Daymont, T. N., \& Andrisani, P. J. (1984). Job preferences, college major, and the gender gap in earnings. Journal of Human Resources, 19, 408-428.

Deere, D., Alvarado, G., \& Twyman, J. (2009). Poverty, headship and gender inequality in asset ownership in Latin America. Working paper, University of Florida, Center for Latin American Studies Gainesville, Fla., USA.

Demeke, M. (2012). Analysis of incentives and disincentives for maize in Ethiopia. Technical notes series, MAFAP, FAO, Rome. http://www.fao.org/3/a-at472e.pdf $\% 20$.

Doss, C. (2002). Men's crops? Women's crops? The gender patterns of cropping in Ghana. World Development, 30(11), 1987-2000.

Doss, C. (2015). Women and agricultural productivity: what does the evidence tell us? Economic Growth Center discussion paper no. 1051.

Duflo, E., \& Udry, C. (2004). Intrahousehold resource allocation in Côte d'Ivoire: Social norms, separate accounts and consumption choices (NBER working paper no. 10498). Cambridge, MA: NBER. http:// www.nber.org/papers/w10498.

Fairlie, R. W. (1999). The absence of the african-american owned business: an analysis of the dynamics of self employment. Journal of Labor Economics, 17, 80-108.

Fairlie, R. W. (2005a). An extension of the blinder-oaxaca decomposition technique to logit and probit models. Journal of Economic and Social Measurement, 30, 305-316.

Fairlie, R. W., \& Robb, A. M. (2007). Why are black-owned businesses less successful than white-owned businesses? The role of families, inheritances, and business human capital. Journal of Labor Economics, 25(2), 289-323.

FAO, IFAD, UNICEF, WFP and WHO. (2019). The state of food security and nutrition in the world 2019. Safeguarding against economic slowdowns and downturns. Rome, FAO. http://www.fao.org/3/ca516 2en/ca5162en.pdf.

Food and Agriculture Organization (FAO). (1996). World food summit: Rome declaration on world food security and world food. Rome: UN Food and Agriculture Organization.

Food and Agriculture Organization (FAO). (2015). Analysis of price incentives for Maize in Ethiopia. Technical notes series, MAFAP, by Wakeyo M. B., Lanos B., Rome. http://www.fao.org/3/a-i4527e.pdf. Retrieved February 12, 2019.

Food and Agriculture Organization (FAO). (2016). Methods for estimating comparable rates of food insecurity experienced by adults throughout the world. Rome: FAO.

Food and Agriculture Organization of the United Nations (FAO). (2011). The state of food and agriculture 2010-2011: Women in agriculture: Closing the gender gap for development Rome. Food Policy, 44, 272-284.

Frey, B. S., \& Stutzer, A. (2002). What can economists learn from happiness research? Journal of Economic Literature, 40(2), 402-435.

Gebre, G. G. (2012). Determinants of food insecurity among households in Addis Ababa city, Ethiopia. Interdisciplinary Description of Complex Systems, 10(2), 159-173.

Gebre, G. G., Isoda, H., Rahut, B. D., Amekawa, Y., \& Nomura, H. (2019a). Gender differences in the adoption of agricultural technology: The case of improved maize varieties in southern Ethiopia. Women's Studies International Forum, 76, 102264.

Gebre, G. G., Isoda, H., Rahut, B. D., Amekawa, Y., \& Nomura, H. (2020). Gender gaps in market participation among individual and joint decision-making farm households: Evidence from Southern Ethiopia. European Journal of Development Research. https://doi.org/10.1057/s41287-020-00289-6. 
Gebre, G. G., Isoda, H., Rahut, B. D., Amekwa, Y., \& Nomura, H. (2019b). Gender differences in agricultural productivity: Evidence from maize farm households in southern Ethiopia. GeoJournal. https://doi. org/10.1007/s10708-019-10098-y.

Greene, W. H. (2012). Econometric analysis. 7th (International) ed. New York University. Pearson. ISBN 13: 978-0-273-75356-8.

Harvest Choice. (2015). Tropical livestock units (TLU, 2005). International Food Policy Research Institute, Washington, DC, and University of Minnesota, St. Paul, MN. http://harvestchoice.org/data/an05_tlu.

Jaleta, M., Kassie, M., Marenya, P., Yirga, C., \& Erenstein, O. (2018). Impact of improved maize adoption on household food security of maize producing smallholder farmers in Ethiopia. Food Security, 10(1), 81-93. https://doi.org/10.1007/s12571-017-0759-y.

Kahneman, D., \& Krueger, A. B. (2006). Developments in the measurement of subjective well-being. The Journal of Economic Perspectives, 20(1), 3-24.

Kassie, M., Ndiritu, S. W., \& Stage, J. (2014). What determines gender inequality in household food security in Kenya? Application of exogenous switching treatment regression. World Development, 56, 153-171.

Kassie, M., Stage, J., Teklewold, H., \& Erenstein, O. (2015). Gendered food security in rural Malawi: Why is women's food security status lower? Food Security, 7, 1299.

Kilic, T., Palacios-Lopez, A., \& Goldstein, M. (2015). Caught in a Productivity Trap: A distributional perspective on gender differences in Malawian agriculture. The World Bank, Washington, USA. World Development, 70, 416-463.

Lutomia, K. C., Obare, A. G., Kariuki, I., \& Muricho, S. G. (2019). Determinants of gender differences in household food security perceptions in the Western and Eastern regions of Kenya. Cogent Food and Agriculture, 5, 1694755.

Mallick, D., \& Rafi, M. (2010). Are female-headed households more food-insecure? Evidence from Bangladesh. World Development, 38(593), 605.

Mango, N., Zamasiya, B., Makate, C., Nyikahadzoi, K., \& Siziba, S. (2014). Factors influencing household food security among smallholder farmers in the Mudzi district of Zimbabwe. Development Southern Africa, 31(4), 625-640. https://doi.org/10.1080/0376835x.2014.911694.

Marenya, P., Kassie, M., Jaleta, M., \& Rahut, D. (2017). Maize market participation among female-and maleheaded households in Ethiopia. The Journal of Development Studies, 53(4), 481-494.

Meinzen-Dick, R., Quisumbing, R. A., Behrman, J., Biermayr- Jenzano, P., Wilde, V., Noordeloos, M., et al. (2011). Engendering agricultural research, development, and extension. IFPRI research monograph. Washington, DC: International Food Policy Research Institute (IFPRI).

Mitiku, A., Fufa, B., \& Tadese, B. (2012). Empirical analysis of the determinants of rural household food security in Southern Ethiopia: The case of Shashemene District. Basic Research Journal of Agricultural Science and Review, 1(6), 132-138.

Mota, A. A., Lachore, T. S., \& Handiso, H. Y. (2019). Assessment of food insecurity and its determinants in the rural households in Damot Gale Woreda, Wolaita zone, southern Ethiopia. Agriculture and Food Security, 8, 1. https://doi.org/10.1186/s40066-019-0254-0.

Mukasa, A. N., \& Salami, A. O. (2015). Gender productivity differentials among smallholder farmers in Africa: A cross-country comparison. Working paper series no. 231, African Development Bank, Abidjan, Côte d'Ivoire.

Mutisya, M., Ngware, M. W., Kabiru, C. W., \& Kandala, N. (2016). The effect of education on household food security in two informal urban settlements in Kenya: a longitudinal analysis. Food Security, 8, 743-756.

Negashi, T. (2019). Predictors of timely initiation of breastfeeding among rural women using case study design in Dawuro Zone, Southern Ethiopia. Journal of Clinical and Medical Research, 1, 1-29.

Njuguna, E., Brownhill, L., Kihoro, E., Muhammad, L., Gordon, M., \& Hickey, M. G. (2016). Gendered technology adoption and household food security in semi-arid Eastern Kenya. In J. Njuki, J. R. Parkins, \& A. Kaler (Eds.), Transforming gender and food security in the global south (pp. 260-282). New York: Routledge.

Njuki, J., Parkins, J. R., Kaler, A., \& Ahmed, S. (2016). Gender, agriculture, and food security: Where are we? In J. Njuki, J. R. Parkins, \& A. Kaler (Eds.), Transforming gender and food security in the global south (pp. 1-18). New York: Routledge.

Nkegbe, K. P., Abu, M. B., \& Issahaku, H. (2017). Food security in the Savannah Accelerated Development Authority Zone of Ghana: An ordered probit with household hunger scale approach. Agriculture and Food Security, 6, 35. https://doi.org/10.1186/s40066-017-0111-y.

Nyikahadzoi, K., Siziba, S., Mango, N., Mapfumo, P., Adekunle, A., \& Oluwole, F. (2012). Creating food selfreliance among the smallholder farmers of eastern Zimbabwe: Exploring the role of integrated agricultural research for development. Journal of Food Security, 4, 647-656.

Oaxaca, R. L. (1973). Male-female wage differentials in urban labor markets. International Economic Review, 14, 693-709. 
Oaxaca, R., \& Ransom, M. (1994). On discrimination and the decomposition of wage differentials. Journal of Econometrics, 61, 5-21.

Ogundari, K. (2017). Categorizing households into different food security states in Nigeria: The socioeconomic and demographic determinants. Agricultural and Food Economics, 5, 8. https://doi.org/10.1186/s4010 0-017-0076-y.

Palacios-Lopez, A., Christiaensen, L., \& Kilic, T. (2017). How much of the labor in African agriculture is provided by women? Food Policy, 67, 52-63.

Peterman, A., Behrman, J., \& Quisumbing, A. (2010). A review of empirical evidence on genderdifferences in non-land agricultural inputs, technology, and services in developing countries. Washington: International Food Policy Research Institute.

Pinstrup-Andersen, P. (2009). Food security: Definition and measurement. Food Security, 1(1), 5-7.

Quisumbing, A. R., Meinzen-Dick, R., Raney, T. L., Croppenstedt, A., Behrman, J. A., \& Peterman, A. (Eds.). (2014). Gender in agriculture: Closing the knowledge gap. New York: Springer.

Ragasa, C., Berhane, G., Tadesse, F., \& Taffesse, A. (2012). Gender differentials in access to extension services and agricultural productivity. ETHIOPIA Strategy Support Program II, working paper.

Shiferaw, B., Kassie, M., Jaleta, M., \& Yirga, C. (2014). Adoption and impacts of improved wheat varieties on food security in Ethiopia.

Sinning, M., Hahn, M., \& Bauer, T. K. (2008). The Blinder-Oaxaca decomposition for nonlinear regression models. Stata Journal, 8, 480-492.

Smith, L. C., Ramakrishnan, U., Ndiaye, A., Haddad, L., \& Martorell, R. (2003). The importance of women's status for child nutrition in developing countries. IFPRI research report 131. Washington, DC: IFPRI.

Sraboni, E., Malapit, H. J., Quisumbing, A. R., \& Ahmed, A. U. (2014). Women's empowerment in agriculture: What role for food security in Bangladesh? World Development, 61, 11-52.

Stutzer, A., \& Frey, B. S. (2010). Recent advances in the economics of individual subjective well-being. Social Research: An International Quarterly, 77(2), 679-714.

Tibesigwa, B., Visser, M., Hunter, L., Collinson, M., \& Twine W. (2015). Gender differences in climate change risk, food security and adaptation: A study of rural households' reliance on agriculture and natural resources to sustain livelihoods. Economic Research Southern Africa (ERSA) working paper 545.

Tura, A. H. (2014). A woman's right to and control over rural land in Ethiopia: The law and the practice. International Journal of Gender and Women's Studies, 2(2), 137-165.

The Economist Intelligence Unit. (2012). Global Food Security Index 2012: An assessment of food affordability, availability and quality. http://foodsecurityindex.eiu.com/. Economist Intelligence Unit. Retrieved January 9, 2020.

Van Hoorn, A., Mabsout, R., \& Sent, E.-M. (2010). Happiness and capability: introduction to the symposium. Journal of Socioeconomics, 39, 339-343.

Westerweel, M., \& Samwel, M. (2014). Gender and food security, a guidance document for practitioners.

Wooldridge, J. M. (2010). Econometric analysis of cross section and panel data (2nd ed.). Cambridge: MIT Press.

World Bank. (2011). World development report: Promoting gender equality and women's empowerment. Washington: World Bank Group.

World Bank. (2012). World development report 2012: Gender equality and development. Washington: World Bank.

World Bank. (2014). Levelling the playing field: Improving opportunities for women farmers in Africa. Washington: World Bank Group.

World Bank, Food and Agriculture Organization, and International Fund for Agricultural Development. (2009). Gender in agriculture: Sourcebook. Washington: World Bank Publications.

World Food Program (WFP) and Central Statistical Agency of Ethiopia (CSA). (2019). Comprehensive food security and vulnerability analysis (CFSVA) of Ethiopia 2019.

Publisher's Note Springer Nature remains neutral with regard to jurisdictional claims in published maps and institutional affiliations. 


\section{Affiliations}

\section{Girma Gezimu Gebre ${ }^{1,2}$ (D) Hiroshi Isoda ${ }^{3} \cdot$ Yuichiro Amekawa ${ }^{4} \cdot$ Dil Bahadur Rahut $^{5,6}$.} Hisako Nomura ${ }^{7}$. Takaaki Watanabe ${ }^{3}$

Hiroshi Isoda

isodah@agr.kyushu-u.ac.jp

Yuichiro Amekawa

yamiko-7@fc.ritsumei.ac.jp

Dil Bahadur Rahut

D.RAHUT@cgiar.org

Hisako Nomura

hnomura@agr.kyushu-u.ac.jp

Takaaki Watanabe

gakuyo@agr.kyushu-u.ac.jp

1 Department of Agricultural and Resource Economics, Kyushu University, Fukuoka, Japan

2 Faculty of Environmnet, Gender and Development Studies, Hawassa University, Hawassa, Ethiopia

3 Faculty of Agriculture, Kyushu University, Fukuoka, Japan

4 Graduate Schools of International Relations, Ritsumeikan University, Kyoto, Japan

5 International Maize and Wheat Improvement Center (CIMMYT), Texcoco, Mexico

6 Asian Development Bank Institute, Tokyo, Japan

7 Development Policy and Management Center for Promotion of International Education and Research, Faculty of Agriculture, Kyushu University, Fukuoka, Japan 